San Jose State University

SJSU ScholarWorks

Master's Theses

Master's Theses and Graduate Research

Summer 2017

\title{
The Perception of Trust Between Athletic Trainers and Musical Performing Artists
}

Jenna Lea Chinburg

San Jose State University

Follow this and additional works at: https://scholarworks.sjsu.edu/etd_theses

\section{Recommended Citation}

Chinburg, Jenna Lea, "The Perception of Trust Between Athletic Trainers and Musical Performing Artists" (2017). Master's Theses. 4842.

DOI: https://doi.org/10.31979/etd.4zxv-m6f7

https://scholarworks.sjsu.edu/etd_theses/4842

This Thesis is brought to you for free and open access by the Master's Theses and Graduate Research at SJSU ScholarWorks. It has been accepted for inclusion in Master's Theses by an authorized administrator of SJSU ScholarWorks. For more information, please contact scholarworks@sjsu.edu. 
THE PERCEPTION OF TRUST BETWEEN ATHLETIC TRAINERS AND MUSICAL PERFORMING ARTISTS

\author{
A Thesis \\ Presented to \\ The Faculty of the Department of Kinesiology \\ San José State University \\ In Partial Fulfillment \\ of the Requirements for the Degree \\ Master of Arts
}

by

Jenna Chinburg

August 2017 
(C) 2017

Jenna Chinburg

ALL RIGHTS RESERVED 
The Designated Thesis Committee Approves the Thesis Titled

THE PERCEPTION OF TRUST BETWEEN ATHLETIC TRAINERS AND MUSICAL PERFORMING ARTISTS

by

Jenna Chinburg

APPROVED FOR THE DEPARTMENT OF KINESIOLOGY

SAN JOSÉ STATE UNIVERSITY

August 2017

Masaaki Tsuruike, Ph.D., ATC Department of Kinesiology

Matthew Masucci, Ph.D. Department of Kinesiology

Shannon David, Ph.D., ATC Department of Health, Nutrition, and

Exercise Science, North Dakota State University 


\title{
ABSTRACT \\ THE PERCEPTION OF TRUST BETWEEN ATHLETIC TRAINERS AND MUSICAL PERFORMING ARTISTS
}

\author{
by Jenna Chinburg
}

Trust is a crucial element for a successful patient-clinician relationship. Athletic trainers may care for musical performing artists who demonstrate unique needs compared to traditional patients. In order to provide the best care, athletic trainers must establish a basis of patient-centered care and build solid professional relationships with performers. By improving overall patient-clinician relationship factors with respect to this population, trust may be implemented and sustained. The purpose of the study was to determine factors that established or diminished trust between drum corps members and their athletic trainers. The study included 12 semi-structured interviews in which Drum Corps International (DCI) members defined and analyzed the perception of trust held within this population in relation to athletic trainer interaction. Trustworthiness techniques of member checks, triangulation, external auditing, connoisseurship, and negative case analyses were used. The qualitative methods determined perception of trust through emergent themes and the effect of trust on the patient-clinician relationship. The study further identified factors that maintained or inhibited the aspect of trust between performer and athletic trainer. Accessibility, clinical competence, dependability, comfort, and having a plan of action were found to be the most prominent themes and promote success within this relationship. Overall, trust plays a role in determining patient rapport, compliance, and timely return-to-play through the patient-clinician relationship in the performing arts setting. 


\section{ACKNOWLEDGMENTS}

The achievement of this thesis would not have been possible without the guidance of my committee members, Dr. Masaaki Tsuruike, Dr. Matthew Masucci, and Dr. Shannon David. In addition, I would like to thank the National Athletic Trainers' Association Research and Education Foundation (NATAREF) for graciously providing a Master's Grant in support of this research. I thank all the DCI athletic trainers who gave assistance in finding participants as well as staff members from across DCI who collaboratively became resources for my literature review. I thank the participants of this study for providing rich, detailed insight of their experiences and for their enthusiasm about the study.

I would also like to thank Dr. Robert Stow who instilled my passion for research and has continuously supported me ever since. Finally, a special thanks goes to all my family and friends for their love and support throughout the completion of my master's degree. 


\section{TABLE OF CONTENTS}

List of Tables........................................................... viii

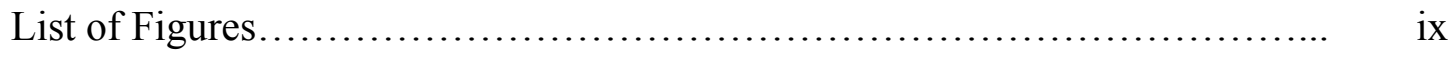

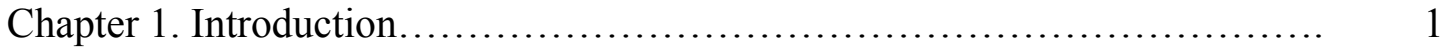

Statement of the Problem............................................ 1

Purpose of the Study................................................. 3

Research Questions............................................... 3

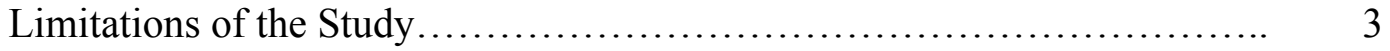

Delimitations of the Study.......................................... 4

Chapter 2. Literature Review........................................ 5

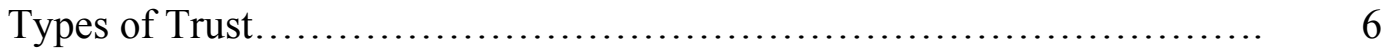

Components of Trust............................................. 8

The Decision to Trust................................................ 9

Importance of Trust in Health Care..................................... 10

Definition of Performing Arts........................................ 12

Types of Performing Arts......................................... 13

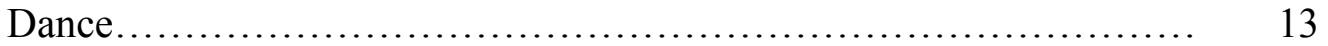

Theatre...................................................... 14

Music............................................................ 14

Other Performing Arts............................................. 14

Marching Band vs. Drum Corps...................................... 15

A Background in Drum Corps....................................... 18

Performing Artists as Athletes........................................ 22

Medical Problems in the Musical Performing Arts...................... 23

General Issues Among Musical Performers/Drum Corps................. 23

Medical Issues Specific to Brass................................... 27

Medical Issues Specific to Percussion............................... 30

Medical Issues Specific to Color Guard/Dancers...................... 32

Trust Between Athletic Trainers and Musical Performing Artists.......... 35

Conclusion.................................................... 37

Chapter 3. Methodology $\ldots \ldots \ldots \ldots \ldots \ldots \ldots \ldots \ldots \ldots \ldots \ldots \ldots \ldots \ldots \ldots \ldots \ldots ., \quad 38$

Research Design............................................... 38

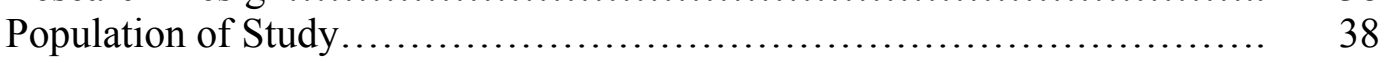

Interview Protocol................................................. 39

Establishing Academic Rigor........................................ 40

Procedures....................................................... 41

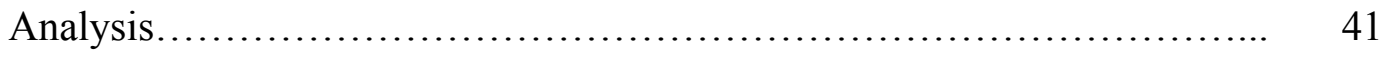


Chapter 4. Results and Discussion........................................ 43

Participant Profile................................................ 43

Interaction with Athletic Trainers in Drum Corps...................... 45

Participant Injury History ........................................ 46

Thematic Analysis................................................. 48

Professional Proficiency ......................................... 50

Professional traits............................................... 51

Availability ................................................ 55

Clinical Credibility ......................................... 60

Interpersonal Dynamics......................................... 65

Personality traits................................................ 65

Advocacy ...................................................... 69

Interaction.................................................. 71

Drum Corps Members' Definition of Trust............................ $\quad 72$

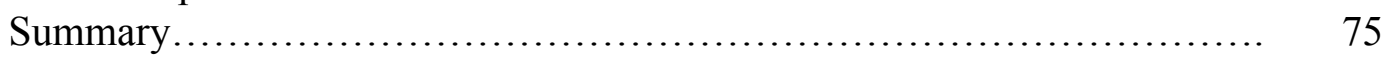

Chapter 5. Conclusions and Recommendations................................ 77

Recommendations for Further Research................................. 79

Clinical Application............................................... $\quad 79$

References.......................................................... 81

Appendices............................................................ 86

Appendix A. Oral/E-mail Script................................... 86

Appendix B. IRB Approval Letter.................................... 88

Appendix C. Interview Protocol........................................ 89

Appendix D. Informed Consent Form............................... 92

Appendix E. Parent/Guardian Consent Form............................ 95

Appendix F. Youth Assent Form...................................... 98 


\section{LIST OF TABLES}

Table 1. Factors of Trust as Perceived by Drum Corps Members................ 50

Table 2. Determination of Medical Coverage Based on Health Care Units......... 58 


\section{LIST OF FIGURES}

Figure 1. Drum Corps Participant Incidence of Injury........................ 47 


\section{Chapter 1: Introduction}

Trust is an attribute that gives medical relationships intrinsic value and increases the likelihood of a successful patient-clinician relationship (Calnan \& Rowe, 2008;

Caterinicchio, 1979; David, 2013). A patient's trust is based on experience and the nature of relationship he or she has with a certain provider (Calnan \& Rowe, 2008). Though the musical performing arts have grown rapidly in popularity over the last decade, the activity remains underserved in terms of medical care. In the performing arts setting, athletic trainers have become the forefront of initial care and are providing services due to their ability to adapt and understand the specific demands of performers (National Athletic Trainers' Association, n.d.; Siegle, 2015).

While implementing a patient-centered approach in athletic training practice, trust can be built through personalization of care with regard to patient feelings, perspectives, and needs (David, 2013). This tactic encompasses the full spectrum of injury care by not only treating the condition at hand, but also doing so in a way that is fitting for the individual. Though the foundational idea of trust is known to be important, it was unknown the extent of trust developed between musical performing artists and athletic trainers.

\section{Statement of the Problem}

Similar to traditional athletes, performing artists have unique needs and face strenuous physical and mental demands (Dick, Dawson \& Miller, 2013). Musical performing artists devote an abundance of time to practicing their instrument or movement patterns and caring for their body as an essential means of performance (Dick et al., 2013). Injury risk remains high due to complexity of physical requirements and 
expectations, although, the performing arts stands as an underserved population with limited access to resources and medical care compared to sport athletes (Bischof, 1994; Dick et al., 2013; Pape, 2014; Siegle, 2015). Since athletic trainers are new to this setting, it is essential for the profession to understand these demands in order to provide the best care and build a solid foundation for trust within the patient-athletic trainer relationship.

Without an understanding of what factors directly inhibited or facilitated trust of a drum corps member with his or her athletic trainer, clinicians were unable to cater treatment outcomes and approaches to successfully fulfill those needs. It also caused ambiguity in interpersonal growth because clinicians were at a loss about what mattered most to these individuals. With sufficient evidence on certain factors of trust strengthening the patient-clinician relationship, athletic trainers can shape the way they practice to fit the population.

Currently, one published work focused on patient trust in the athletic training setting and it did not evaluate the performing arts (David, 2013). Though trust has been evaluated in other professions such as nursing (Radwin, Washko, Suchy, \& Tyman, 2005), psychotherapy (Drain, 2001), and general medicine (Anderson \& Dedrick, 1990), it is difficult to translate results to athletic training due to differences in scope of practice, working circumstances, and populations reached. This represented a critical knowledge gap for the profession since it was unknown whether the relationship between athletic trainer and patient was influenced by trust beyond the collegiate setting. 


\section{Purpose of the Study}

The purpose of this study was to determine factors that establish or diminish trust between drum corps members and their athletic trainer. Researching this specific population allows clinicians to better understand the needs of musical performing artists and more effectively facilitate the patient-clinician relationship.

\section{Research Questions}

1. What factors influence trust between the performer and athletic trainer?

2. To what extent does the perception of trust influence the relationship between drum corps members and athletic trainers?

\section{Limitations of the Study}

There was a sampling limitation due to drum corps being selected for participation based on members having direct access to an athletic trainer throughout the summer months of physical activity. In total, only nine of the 23 World Class drum corps previously or currently have an athletic trainer on staff. Though this shows the need for athletic trainers within the setting of musical performing arts, it is unknown if the interviews created a true representation of the population of interest.

The concept of saturation also posed a limitation. Although saturation is supported by research to guide the number of participants interviewed, it is impossible to predict whether or not the research could have gained more value by interviewing additional individuals (Guest, Bunce, and Johnson, 2006). Time constraints on interviewing represented another limitation. With more time and additional questions, there would be potential for new data to surface. 


\section{Delimitations of the Study}

The study was focused on one specific facet of musical performing arts. Drum and bugle corps are prominent groups of interest; however, this research did not take into account other amateur or professional musical performing artists or groups. Thus, inferences and generalization about factors of trust were solely based on the population studied without claim that the results and/or opinions would extend to other musical performing artists. 


\section{Chapter 2: Literature Review}

The purpose of this study was to evaluate the amount of trust performing artists, specifically drum corps members, had in their athletic trainer. Through the determination of specific factors that influenced trust, the patient-clinician relationship between performing artist and athletic trainer could be better understood. This chapter is organized into the following areas: trust definition, types and components of trust, importance of trust in health care, definition of performing arts, types of performing arts, explanation of drum corps, and medical problems in the musical performing arts.

Trust is an essential concept for a successful patient-clinician relationship (David, 2013). The word within itself has various connotations and perceptions. As stated by Mayer, Davis, and Schoorman (1995) trust is defined as "the willingness of a party to be vulnerable to the actions of another party based on the expectation that the other will perform a particular action important to the trustor" (p. 712). Many general definitions of the term focus on the assumption of confidence within another person or entity (Dictionary.com, n.d.; Merriam-Webster, n.d.). Additionally, trust is thought to be in conjunction with dependence or reliance on someone or something (Merriam-Webster, n.d.).

In a medical sense, Anderson and Dedrick defined trust of a physician as "a patient's set of beliefs and expectations that a physician will behave in a credible way" (1990, p. 1093). Patient trust has also been defined as "a reassuring feeling of confidence or reliance in the physician's capacity and intention to provide psychological and/or physical relief from illness or condition" (Caterinicchio, 1979, p. 82). These definitions 
examine the potential for a physician's (or allied health professional's) ability to provide care as a factor in gaining trust. Most applicable to this thesis, David created a definition of trust specific to the setting of athletic training: "Trust is a belief (and/or a feeling) that an athletic trainer has the patient's best interest in mind and that therapy, and any associated information provided during therapy, will help the patient return to activity" (2013, p. 98).

After reviewing the literature and gathering opinions from experts on trust, it can be concluded that trust is a multi-faceted concept (Borum, 2010). As previously stated by several of the definitions above, trust involves the ability to become vulnerable and exposed in order to gain openness or understanding of another person or idea. It also can involve feelings of faith, comfort, agreement, and honesty depending on the context. Often, trust requires the prediction or assumption of a situation and the subsequent benefits to be obtained (Borum, 2010). Once gained, trust is a bond that must be nurtured in order to develop and extend in a long-lasting manner (Borum, 2010).

\section{Types of Trust}

Many types of trust exist within the health care profession (Borum, 2010; Hall, Camacho, Dugan, \& Balkrishman, 2002; Starnes, Truhon, \& McCarthy, 2010). Among overarching health care companies and facilities, organizational trust is established (Starnes et al., 2010). This type of trust can be divided into two forms: interorganizational trust and intraorganizational trust (Starnes et al., 2010). Starnes and colleagues (2010) explained interorganizational trust as the trust between two organizations (such as a hospital and United Parcel Service) and intraorganizational trust as the trust between 
workers and their immediate supervisors or workers and those running the organization. For purposes of this thesis, the focus will remain on interpersonal trust. Nevertheless, it should be understood that interpersonal trust plays a role in the foundation of organizational trust (Starnes et al., 2010).

Hall and colleagues (2002) described interpersonal trust as "a relationship between two individuals where one individual is vulnerable to decisions made by another" ( $\mathrm{p}$. 1421). Interpersonal trust is claimed to be the most pivotal yet least directly measured aspect affecting individuals and organizations in human-centric environments (Borum, 2010). It can be impacted by various factors within the health care setting including the patient's right to choose a physician or allied health care professional (David, 2013). If given the opportunity to make a personal choice regarding health care providers, patients will likely start with a higher sense of trust in their provider compared to those who cannot choose (Barefoot, Maynard, Beckham, Brummett, Hooker \& Siegler, 1998; Hall et al., 2002).

Traditionally, trust has been thought to emerge in interpersonal relationships over the span of time (Borum, 2010). Varying opinions exist on how interpersonal trust is formulated between two people. Some believe humans determine trustworthiness of others because of some positive emotion or belief being activated (Mayer et al., 1995); others argue its basis on negative expectation or emotion, such as fear or anxiety (Borum, 2010). Regardless of theory, it is clear that trust may be a crucial factor in improving the patient-clinician relationship (David, 2013). 


\section{Components of Trust}

Mayer and colleagues (1995) state that trust may be a "concept affected by different precursors." One of the essential precursors includes trustworthiness. Though the root word is imbedded within the concept, trust and trustworthiness are not the same and should be defined separately. A common distinction defines trust as a person's "willingness to accept vulnerability to another conditioned on expectations regarding the other's behavior" (Borum, 2010, p. 1). When determining trustworthiness of another person, the concept is subjective based on the individual's personal perceptions and benefits. Trustworthiness may be viewed as the key antecedent of trust rather than a parallel with the actual behavior of trust itself (Borum, 2010).

Another component of trust is competence or the ability to do something well (Borum, 2010). Mayer et al. (1995) confirmed competence to be a determinant of trustworthiness stemming back to the works of Aristotle, which has continued through the writings of contemporary authors. Based on patient care, if the medical personnel are well regarded in their profession it should be an easier task to facilitate trust. To expand on this, David explains how athletes' trust of a medical professional is often swayed by teammate opinions and experiences (2013). Many authors have also agreed upon benevolence as an additional component of trust (Borum, 2010; Mayer et al., 1995; Peters, Covello, \& MacCullum, 1997).

According to Borum (2010), the notion of benevolence is based on perceptions of care, goodwill, empathy, responsibly fulfilling obligations, and goal commitment. Often, patients become non-compliant to treatment suggestions if the medical professional does 
not exhibit a sense of care for their specific condition. The perception of quality time spent (regardless of actual amount of time) with the patient instills a perception of having his or her best interest in mind.

Similarly, integrity is considered a component of trust (Borum, 2010; Mayer et al., 1995; Peters et al., 1997). Integrity is "rooted in appraisals of a trustee's objectivity, fairness, and accurate/honest communication and also supports the trustee's perceived dedication or commitment to the goal" (Borum, 2010, p. 14). Without being upfront and honest with a patient, the health care professional hinders a natural ability to bond with him or her on a personal level. Proper communication skills and the ability to talk with a medical professional play a key role in patient adherence (Barefoot et al., 1998; Dwyer et al., 2012).

The final component of trust as stated by McKnight and Chervany (2001) is predictability. It is defined as “believing the other party's actions (good or bad) are consistent enough that one can forecast them in a given situation" (p. 49). As humans, we generally struggle with change and are better prepared to manage it if seen as forthcoming. When offering medical services to a patient over a prolonged period of time, he or she will formulate expectations based on past experiences; therefore, the medical professional should remain consistent not only with that specific patient but also with all patients considered.

\section{The Decision to Trust}

Trust is reliant on a rational choice model in which individuals choose a course of action based on egocentric perception (Borum, 2010; Dionisi \& Brodt, 2008; Homans, 
1958). This model suggests "people are motivated to maximize personal gains and minimize personal losses in social interactions by reacting to other individuals from a self-interested perspective" (Kramer \& Tyler, 1996, p. 1). People constantly evaluate the outcomes and worth of a decision and typically choose based on the prospect of benefit (Borum, 2010). In addition to the analysis of potential benefits, trust has a component of development (Borum, 2010). It progresses over time and across relationships as information reveals potential for an individual to be trusted (Weber, Malhotra, Murnighan, 2005).

\section{Importance of Trust in Health Care}

Trust is the element that instills inherent value in medical relationships (Calnan \& Rowe, 2008). In a comparative case study of trust relations between patients, health care professionals, and health service managers, it was determined through observation and reporting that trust cannot be assumed (Calnan \& Rowe, 2008); instead, trust must be earned and viewed as conditional (Calnan \& Rowe, 2008). Patient trust is based on experience and the nature of the relationship one has with a particular provider.

Many studies have been completed on the level of trust between patients and physicians. Hall and colleagues (2001) gathered information specifically on physician trust and found the foundation of trust to be strongly indicated by treatment aspects rather than social interaction. The researchers concluded that trust was critical to the patient's compliance in seeking care and willingness to disclose sensitive information as well as the patient's ability to abide by physician recommendations (Hall, Dugan, Zheng, \& Mishra, 2001). Additionally, the frequency of successful treatments and health gains 
perceived as positive from treatment also factors into the patient-physician relationship (Caterinicchio, 1979). If the patient feels as though the physician is trustworthy and able to produce successful results, the patient is likely to return to that specific provider.

Dwyer, Liu, and Rizzo (2012) proposed that patient trust is factored into three domains of physician attributes: technical competency, interpersonal competency (communication between physician and patients), and fidelity (putting patient health and well-being above other concerns when making decisions). These attributes are not seen as mutually exclusive. Patients have considered the ability to talk to a doctor on a personal level as one of the most valuable physician attributes (Barefoot et al., 1998; Dwyer et al., 2012).

A physician's behavior can greatly influence a patient's capacity to trust. Barefoot et al. (1998) focused his study on evaluation of trust and patient-reported outcomes suggesting that higher levels of trust were linked with better self-report of overall health status and general functional health. A low amount of trust was attributed to failure to seek health care. To defend this point, Ozawa and Sripad (2013) also determined trust to be associated with satisfaction and dependability of the physician. Patient trust changes as individuals experience more direct interactions with their physician (Dwyer et al., 2012). Without proper care, the patient may choose to seek other options best suited to their needs.

Beyond the relationship of patient and physician, trust has also been evaluated in other professions including nursing, psychotherapy, and emergency medicine. The nursing study tested four desired health outcome scales including a piloted Trust in 
Nurses Scale. In discussion, the mean of this scale was particularly high (87.75/100). An additional anecdote referred to a Gallop poll indicating that nurses, as well as several other professions, bode well with the public when ranked for honesty and ethics which may inspire trust (Radwin et al., 2005). From other authors, a systematic review was completed on trust within the entire health care system (Ozawa \& Sripad, 2013). Regardless of health profession or affiliation, Ozawa and Sripad discovered the relation of trust with several health care objectives including accessibility, health-related behavior, quality of care, and self-reported health status (Ozawa \& Sripad, 2013).

Of the research gathered from other health care professions, it is expected that athletic trainer behavior can also influence trust among patients (David, 2013). Unfortunately, besides one published work, there appears to be no other research to measure patient trust within the setting of athletic training. This posed a knowledge gap for the profession since it was reasonable to presume, like any other health care field, that the relationship between athletic trainer and patient would be established and, therefore, influenced by trust and quality of care (David, 2013). It was beneficial to examine trust in athletic training rather than relying on other disciplines' findings due to educational differences, number of hours worked, and individuals reached.

\section{Definition of the Performing Arts}

Similar to trust, the phrase "performing arts" has various definitions and opinions carried within the term. The most basic definitions state "a form of creative activity that is performed in front of an audience, such as drama, music, and dance" (Oxford Dictionaries, n.d.) in addition to "a type of art that is created in front of or presented to an 
audience by the artist" (Merriam-Webster Online, n.d.). Both definitions include the aspect of an audience's presence and the inclusion of an art form, but remain vague without any expansion of detail. More applicable to this thesis, Manchester (2009) developed a definition of performing arts specific to the realm of sports medicine: "the performing arts include a range of human activities that occur in front of an audience (at least some of the time) and attempt to add to our understanding, appreciation, and/or celebration of the human experience" (p. 102).

Often, performing arts is misconstrued in the medical field as a hobby rather than a physical activity. Many clinicians find it hard to decipher a well-rounded definition comparing "artistic sports" such as figure skating and gymnastics with performing arts. For this reason, Manchester (2009) found it necessary to solidify a definition for the purpose of performing arts medicine in order to understand the specific needs of performers. The activity may or may not involve some form of competition since that aspect is not always the primary reason for participation. It also requires varying amounts of energy expenditure dependent on the demands, individual capabilities, and nature of the activity.

\section{Types of Performing Arts}

Dance. The art of dance includes various genres including, but not limited to ballet, tap, jazz, hip-hop, lyrical, and ballroom. Each has their own particular style and encompasses the aspects of emotional storytelling and character development through use of body language and movement (Dance USA, n.d.). In total, the United States has 353 dance companies listed on the national roster with budgets above $\$ 100,000$ (Dance USA, 
n.d.). Dance companies range in skill level from amateur to professional and generally focus on one type of genre such as ballet, contemporary, or cultural specific.

Theatre. Theatre can be defined as the reenactment of stories taken from literary resources or creative works usually communicated through spoken word, song, or gestures (Brown, 1997). This art form incorporates performers of all ages and embraces the act of storytelling through visual interpretation (Brown, 1997). According to Cengage (n.d.), at least one professional theatre company exists in each of the United States, though some states have more or less dependent on demand and population of the area (e.g. Alaska has 2; California has 47).

Music. Music is proclaimed as the most universal of the performing arts and is found in every society and culture (UNESCO, 2012). It can be conveyed either instrumentally, vocally or a combination of both. Notes are arranged and played or sung in a fashion to elicit a message. Instrumental music incorporates harmonies and melodies to resemble or evoke certain emotions (National Band Association, n.d.). Within the overarching entity of instrumental music are various ensembles. This includes orchestra, wind symphonies, concert bands, marching bands, and drum and bugle corps to name a few. One of the most recognizable music ensembles to the general public is marching band due to a longstanding history and social presence at many events.

Other performing arts. In addition to dance, theatre, and music, a few specialized art forms exist within the realm of performing arts. Circus, magic, and illusion art all require a live audience and special effects to achieve their goal as entertainers and 
performers. Often elaborate props and costumes are used in order to blur the line of perceived and actual reality.

\section{Marching Band vs. Drum Corps}

Marching band is generically defined as "an ensemble of musicians that march in time to music for entertainment at events, often with brass, wind, and percussion instruments, drum majors, and color guard" (Dictionary.com, n.d.). Typically, marching bands perform at venues such as football games, parades or community events (J. Erdman, personal communication, December 5, 2014). Most are affiliated with a high school or university in which they dress in the school colors and help represent the spirit of the student body as well as the school as a whole (J. Erdman, personal communication, December 5, 2014). These bands contain musicians of all musical abilities, body types, and interests (R. Marquis, personal communication, November 18, 2014). Fundamental concepts of music such as rhythm, tone, balance, style, and interpretation are all incorporated in learning (I. Behlke, personal communication, September 30, 2014). Often, music educators will stress the balance between melody and harmony with these groups (I. Behlke, personal communication, September 30, 2014).

Marching band is offered either as an extra-curricular activity or as a class ( $\mathrm{T}$.

Williams, personal communication, December 29, 2014). Sometimes if enrolled in a band program, marching band will be part of a class requirement. The cost and number of staff available is dependent on many factors including regional expectations, size of the band, school budget, and travel (J. Erdman, personal communication, December 5, 2014). A band program may only have one band director to oversee not only the marching band, 
but also all of the other music ensembles such as concert band and orchestra (J. Erdman, personal communication, December 5, 2014).

In high school, marching bands are separated into "competition" and "noncompetition" bands which is determined by whether the band participates in musical competitions against other competitive marching bands (R. Marquis, personal communication, November 18, 2014). By doing so, the band will likely have access to more funding or specialized staff who work solely with brass, percussion, and color guard. This is also seen in larger bands such as those affiliated with a college or university. Additionally, dependent on size, interest, and venue availability, marching bands are targeted toward various populations.

Drum and bugle corps (often referred to as drum corps for short) is described as "an intense, choreographed musical experience staged on football stadium fields by students achieving high levels of excellence in performance" (Drum Corps International, n.d.). Bischof (1994), a medical doctor with previous experience in the activity, also referred to drum corps as "a popular, unique activity that combines elements of music, sports, the arts, and competition" (p. 131). Unlike marching band, drum corps are only composed of brass players, percussionists, front ensemble, and color guard.

All drum corps are non-profit organizations. Some corps partner with a parent organization for funding (DCI, n.d.). To offset operational costs, each participant or "member" must pay member fees and audition fees if an audition is required for that corps (T. Vou, personal communication, January 5, 2015). Member fees roughly range between $\$ 2,000$ and $\$ 4,000$ each year and include food, lodging, transportation (with the 
exception of flights), uniforms, and instruments ( $\mathrm{T}$. Vou, person communication, January $5,2015)$. The activity of drum corps is known as an immersive experience due to its extensive, time-consuming nature in which the performer solely focuses on the task at hand and how to improve not only as an individual, but as a unit (T. Williams, personal communication, December 29, 2014). The Drum Corps International website refers to the activity as "marching music's major league."

In addition to higher funding, drum corps require a larger staff. Each section (brass, percussion, and color guard) has several individuals specialized in and devoted to that area known as technicians (Weber, 2010). Caption heads are the staff that oversee each section and section's staff members (Weber, 2010). In conjunction with the instrumental instructional staff are visual instructional staff that ensure the desired vision of the show is being executed properly and members are successfully creating the picture or "form." Most staff members employed with drum corps have participated in one previously and have some sort of musical background whether it be a degree in music education or currently holding a position as a band or music director (R. Marquis, personal communication, November 18, 2014).

Administrative staff manage the day-to-day operational needs of the organization (Weber, 2010). Furthermore, many volunteers (often parents and alumni) assist with necessary tasks such as driving buses/trucks, caring for the corps' uniforms, and preparing meals for the corps (Weber, 2010). Medical personnel are either paid staff or volunteers based on the corps' budget and help to care for the health and wellness needs of members and staff. 


\section{A Background in Drum Corps}

The beginnings of drum corps trace back to fife and drum corps of the $19^{\text {th }}$ century (Bischof, 1994). These groups consisted of fife (woodwind) players and drummers. Bugles or horns were gradually added to give fife players a rest during performances (Bischof, 1994). In the $20^{\text {th }}$ century, corps started associating with Roman Catholic parishes, which eventually expanded to affiliations with the American Legion and VFW post-World War I (Bischof, 1994). During the early 1930’s, drum corps began to take on characteristics of modern-day groups (Bischof, 1994).

Current drum and bugle corps consist of three competitive classes. World Class is the most well-known with up to 150 members, primarily college aged, performing at 30 to 40 scheduled events while traveling over 10,000 miles across $15+$ states throughout the course of a summer (DCI, n.d.). In total, there are 23 World Class corps based out of 16 states (DCI, n.d.). Members can participate in any corps of their choosing, but must audition for a spot via video or in person and become contracted in order to march the following summer (DCI, n.d.).

Open Class corps require a minimum of 30 members up to a maximum of 150 and follow a condensed tour schedule with primarily high school students (DCI, n.d.). This class is comprised of 23 corps and auditions are not always required (DCI, n.d.). Finally, the third class of drum corps is international. International Class corps are from outside North America who travel to perform as part of the annual Drum Corps International tour (DCI, n.d.). Regardless of class, each member must be 21 years old or younger to participate (DCI, n.d.). There is not a set minimum age; however, most World Class 
corps prefer their members to be at least 15 or 16 years of age. Open Class corps have members as young as 7 participating (J. Erdman, personal communication, January 10, 2015). Many drum corps also have senior corps composed of alumni that primarily function at parades or indoor events.

Due to the focus for this thesis being World Class drum corps, it is necessary to expand on the logistics of what a "tour" entails. Auditions occur November through January each year. If contracted, the member must also attend a weekend long camp once a month from January through April. This is where the corps begins to learn the music and start physical training such as running, agility, and marching basics (R. Marquis, personal communication, November 18, 2014). The bulk of activities take place during the summer due to most members being full-time high school or college students. The months of May through early August are devoted to a full schedule of rehearsals, competitions, parades, and other performances (Bischof, 1994). Besides two to three "free days" or off days where members have no rehearsal or competition obligations, each hour of every day is systematically planned with drum corps activities.

Roughly, the first month of summer is referred to as "spring training" or "move-ins" where the corps stays in one or two designated locations. Staff or volunteers prepare meals four times per day out of a fully functional kitchen truck. During this time, the members collectively begin to learn the basic drill or formations that compose their show which is used to compete against other drum corps later in the summer at competitions (T. Williams, personal communication, December 29, 2014). A show is approximately eight to twelve minutes in length and is split into sets. Usually, an entire show contains 
150-200 sets with varying number of steps in each set (Pape, 2014). For example, an eight-to-five step size indicates that there are eight steps between every five yards on the football field (Pape, 2014).

Drill becomes increasingly difficult when step sizes increase (such as six-to-five instead of eight-to-five), requiring members to either lengthen their stride or run set to set. Depending on the change in form, sometimes backwards or diagonal marching is necessary to navigate across the field (Pape, 2014). Tempos are frequently set at 180-200 beats per minute with the expectation of taking four or five steps (Pape, 2014). In short, performers are moving up to 12 feet per second or 8.18 miles per hour for extended time while simultaneously blowing air through their instruments or handling equipment (Pape, 2014). Despite the fast-paced movements, rehearsal days usually consist of three blocks of three to four hour practice time starting around 8:00 am and ending at 9:00 pm or 10:00 pm. As an example, after breakfast members participate in visual rehearsal followed by lunch, then sectionals to work on music, dinner, and finally, ensemble rehearsal to finish the day (Pape, 2014). In visual rehearsal and sectionals, brass, color guard, and percussion typically split into their respective sections to work on needed areas. Ensemble rehearsal is where the entire corps comes together to solidify the production.

In early June, tour starts in which the corps travels to various venues across the country to compete against other drum corps at competitions. Several professional judges affiliated with DCI score the competitions. The highest achievable score is 100, although; most corps begin tour receiving a score in the range of 60-70 (T. Williams, personal 
communication, December 29, 2014). Each corps is judged on general effect of the show, visual components, and music (Weber, 2012). Based on the judges' comments and interpretations, the corps will improve, add, and sometimes completely alter their show, in attempt of obtaining a higher score at the next competition. Days in between competitions continue to be 12-hour rehearsal days with some appearances for special events such as parades or concerts. This coincides with traveling to the next destination. All transportation is conducted via coach busses with departure often occurring in the evening and arrival either late night or very early morning.

Each competition leads up to arguably the most exciting part of the summer: DCI World Championships. This portion of tour is held the last three days of the season during the first week of August starting with prelims (DCI, n.d.). All 23 World Class corps perform in addition to any Open Class corps who wish to participate featuring more than 35 corps in total ("Day-by-day guide to the 2014 DCI World Championships", 2014). The following day is semifinals, which features DCI's top 25 corps as determined by the preliminary event ("Day-by-day guide to the 2014 DCI World Championships", 2014). The day after semifinals is World Championship finals where the top 12 drum corps compete for the opportunity of becoming World Champion ("Day-by-day guide to the 2014 DCI World Championships”, 2014).

To be expected, members push their bodies to maximal limits within the last few weeks of tour to prove to judges and fans that they deserve a top 12 spot at World Championships. Many acute injuries ensue and threaten the ability to finish out the most important aspect of the season. Members must trust medical personnel on the sidelines 
(e.g. athletic trainers) to safely rehabilitate such injuries and implement safe return-toplay protocol for performance readiness. Without a solid relationship between athletic trainer and performer, members may miss out on performance opportunities or develop serious injuries or conditions carrying beyond the summer drum corps experience.

\section{Performing Artists as Athletes}

Similar to a traditional athlete, performing artists have a brief off-season, intentionally push through pain, compete in severe environmental demands, and face the risk of long-term injury (Dick et al., 2013). Work schedules of a professional performing artist parallel to that of a professional baseball player. Both perform or play with a schedule consisting of more than 150 games or performances per season (Dick et al., 2013). Their routine becomes habitual with a high possibility of disturbed eating patterns and sleeping habits (Dick et al., 2013). Additionally, each face extreme competition in which focused training and skill is required in order to win or score higher than the opponent.

The performing artist's body, similar to a sport athlete, contributes significantly to their success in performance (Dick et al., 2013). Musicians and performing artists must devote time to practice their instrument or routine in addition to caring for their bodies. Injury risk is relatively high due to a complex combination of physical requirements and capabilities (Bischof, 1994; Dick et al., 2013; Siegle, 2015). With musical performing artists, strength, coordination, and endurance are required for supporting large instruments such as tubas and percussion (Dick et al., 2013). Focal coordination is also 
needed for hand and forearm muscles due to quick, repetitive motions for a majority of time (Dick et al., 2013).

Respiratory control is necessary to provide sufficient air through the instrument when playing for extended periods. Performers use more than 20 orofacial muscles to hold a proper embouchure continually while participating (Dick et al., 2013). Playing an instrument emphasizes an increased risk of physical issues, which compares to a traditional athlete becoming injured from the nature of the sport (Dick et al., 2013). Unfortunately, the performing arts are an underserved population (Dick et al., 2013, Siegle, 2015). A professional sport athlete has access to numerous resources including dietary plans or restrictions, adequate medical care for injury prevention and rehabilitation, video replay to visualize mechanics, and sport psychologists for mental health conditions (Dick et al., 2013). Performing artists have few, if any, of these resources and yet the same needs (Dick et al., 2013). Currently, allied health care professionals have a significant knowledge deficit and lack the understanding on how to properly care for these individuals (Dick et al., 2013).

\section{Medical Problems in the Musical Performing Arts}

Though many medical issues are in conjunction with repetitive movement patterns or specific mechanics, several conditions are common among all musical performing artists.

General issues among musical performers/drum corps. Noise-induced hearing loss (NIHL), caused by ongoing noise exposure and duration, is one of the most prevalent health conditions among this population (Dick et al., 2013). During the initial years of exposure, NIHL increases exponentially with daily sound levels exceeding $85 \mathrm{~dB}$ over an 
eight-hour period (Dick et al., 2013). The daily-recommended maximum exposure for 94 $\mathrm{dB}$, equivalent to an MP3 player at half volume, is one hour and for $100 \mathrm{~dB}$, equivalent to an MP3 player at full volume, is 15 minutes (Dick et al., 2013). Drum corps tremendously exceed this daily maximum limit putting individuals at high risk for NIHL. Special concern should be placed on percussionists due to increased sound from the drum head and the projection of sound traveling upward rather than out (M. Mastriforte, personal communication, November 14, 2014).

Music itself is not considered the issue in causing NIHL, however, the loudness and duration are of concern (Dick et al., 2013). Temporary NIHL can be cured with adequate rest and recovery, but permanent NIHL has unfortunately been found to be irreversible (Dick et al., 2013). Currently, there are no known treatments or cures for this issue besides preventative measures (Dick et al., 2013). Requiring all members to wear protective earplugs is the best way to ensure the proper function of hearing (Dick et al., 2013). Although athletic trainers can do little to prevent hearing loss conditions, education can become a key factor in patient adherence to noise reduction and building a patient-clinician relationship through clinical competence.

Additionally, overuse injuries are common among all sections due to repeated stresses on the body with little to no recovery period to heal (Dick et al., 2013; Siegle, 2015). The physical demands of musical performing artists in conjunction with playing duration and intensity exceed physical adaptation of the body (Dick et al., 2013). Excessive load on the lower extremity causes injuries such as metatarsal and tibial stress fractures, medial tibial stress syndrome, and patellofemoral pain syndrome (Siegle, 2015). These chronic 
injuries and general musculoskeletal issues are commonly seen within the scope of practice in athletic training which places greater need for these professionals in the performing arts setting. Improper posture is another key component to the development of an overuse injury (Dick et al., 2013). Although drum corps may travel with a few alternate members, a substitution of one uninjured member for an injured one is not an easy task (Siegle, 2015). To substitute a member for an alternate requires learning specific step counts and spots on the field, which is completely different than following along on the sidelines (Siegle, 2015). Regardless of training regiment, overuse injuries are inevitable in this activity due to the disproportionate ratio between performing and rest.

Musculoskeletal injuries, both acute and chronic, factor into widespread issues for this population (Bischof, 1994; Dick et al., 2013; Siegle, 2015). In one study, muscle strains were reported most frequently (54\% of those surveyed) among acute injury within a drum corps (Bischof, 1994). Acute strains and sprains commonly occur in daily activity, sometimes when performing or rehearsing on unstable surfaces (Siegle, 2015). With such a high prevalence of acute injury, it is crucial for drum corps members to trust their athletic trainer or medical professional in order to perform at their best potential without further damage. Chronic issues such as tendonitis and bursitis are caused by repetitive overuse, marching technique, and habitual movement patterns (Bischof, 1994). Musicians often play with excessive muscle tension, which translates into regions of the body not used for playing the instrument (Dick et al., 2013). This increased tension can become a deficiency to the performer and an unnecessary mechanism of injury. Proper 
warm-up and cool down, stretching, and frequent breaks are essential to aid in prevention of these injuries (Dick et al., 2013). With an athletic trainer's help and expertise, conditioning and rehabilitation protocols can be implemented as a means of injury prevention.

Due to the activity primarily taking place throughout the summer, heat illness is of concern (Bischof, 1994; Pape, 2014; Siegle, 2015). Depending on whether the corps is on the East Coast or West Coast, a significant amount of time may be spent in the Southern states where high temperatures and humidity are difficult to escape. Members of the corps are from all parts of the country in which some may not be as accustomed to such extreme heat. Inadequate hydration and nutrition intake pose initial threats when exercising at strenuous levels (Bischof, 1994). Additionally, sunburn ranked as the most frequent response (84\%) on a survey measuring drum corps injury (Bischof, 1994). High prevalence of sunburn drastically increases susceptibility to heat illness.

Though members are offered four meals per day, some face nutritional deficiencies due to lack of appetite, excluding foods from their diet, or simply not eating enough. Water and Gatorade are available all day, however, many misjudge the amount of fluid lost during rehearsal and do not drink enough during meals. Rehearsing or performing in a dehydrated state decreases available energy and nutrients to active muscle, therefore, impairing performance (Dick et al., 2013). It is crucial to fuel the body for performance with plenty of carbohydrates especially three to four hours prior to competition (Dick et al., 2013). After a long day of rehearsal or finishing a show, many members want to relax and quickly fall asleep, though; post-event eating helps to ensure readiness for the next 
day (Dick et al., 2013). The earlier food or drink can be ingested after activity, the quicker energy stores are replenished.

Several general medical conditions pose a problem to certain individuals with susceptibility. Allergies and exercise-induced asthma are easily treated with medication, though, can become irritating especially with an increased number of allergens during the summer months. A combination of prolonged exercise and summer heat exposes asthmatics to an increased possibility of acute asthma attacks and overuse of inhalers. Gastrointestinal issues such as diarrhea and constipation are prevalent due to fluid imbalances, altered eating habits, and disruption of regular routine. Often, outbreaks of illnesses and infections such as tonsillitis, bronchitis, ear infections, and flu occur throughout the summer. The closeness in proximity to others, frequent travel, environmental factors, and the sharing of personal items are all mechanisms for the illness or infection to spread. Many members are under the age of 18 and may only feel comfortable discussing medical issues with a primary doctor or parent/guardian. Since parents are not readily available except via phone call or e-mail, an athletic trainer must establish an aspect of approachability and confidentiality through interactions with members. This allows for the athletic trainer to create a trusting bond with individuals as the primary medical provider especially with conditions that are difficult to discuss or sensitive for the performer.

Medical issues specific to brass. Focal dystonias are common among all instrumental performing artists, though brass players tend to develop them along the facial musculature (Dick et al., 2013). Dick and colleagues (2013) describe a focal 
dystonia as "an abnormal movement disorder that develops when a person is attempting to perform a specific task" (p. 389). Embouchure places varied stresses on the lips and facial features determining whether a dystonia forms. The corners of the mouth are pulled tighter when trying to play high notes; however, this should not cause strain of the cheeks and jaw (J. Erdman, personal communication, December 5, 2014). While playing a brass instrument, sound is created by "buzzing" or resonating the lips rapidly into the mouthpiece. A performer's embouchure is affected by the production of air, tonguing technique, and use of facial musculature (J. Erdman, personal communication, December 5 , 2014). Though this should not factor into the development of a dystonia, some brass players use a wet embouchure instead of a dry embouchure in which they lick their lips before playing. Often, a focal dystonia can be treated with medication, biofeedback, relaxation techniques or simply changing equipment or technique (Dick et al., 2013). Another unique problem associated with brass is mouthpiece dermatitis. Generally, dermatitis is defined as inflammation of the skin. In regard to this particular condition, brass players press the mouthpiece with increased pressure directly into the lips, teeth, and philtrum (Bischof, 1994). This causes edema, erythema, or numbness to the philtrum, which may affect the sound produced in the instrument as well as the ability to play the instrument correctly (Bischof, 1994). With proper embouchure and moderation of playing time, this condition can be easily avoided (J. Erdman, personal communication, December 5, 2014). It is crucial for brass players to recognize the amount of shear forces placed on their mouthpiece in order to avoid further injury. If another performer or piece of equipment bumps an instrument while moving through formations, lip lacerations or a 
chipped/avulsed tooth may occur (Bischof, 1994). Dependent on the severity, athletic trainers can assist with proper wound care to prevent infections. Many mouthpieces are made out of silver-plated material that can also cause nickel-allergic contact dermatitis (Bischof, 1994). Though irritating for the performer, mouthpieces manufactured from other metals are available for purchase and will quickly alleviate symptoms (Bischof, 1994).

Blisters, calluses, and corns can become a nuisance for this population due to hold and carriage of the instruments. The affected areas often form a characteristic pattern and can be distinctive to the particular musician (Bischof, 1994). Baritone players most commonly have discomfort or pain in the second and third metacarpophalangeal joints on the left hand due to the heavy weight distribution of the instrument in that area (Bischof, 1994). Due to the finger hook placement being in front of the valves, trumpets and baritones develop calluses along the radial aspect of the distal interphalangeal joint of the fifth finger on the right hand (Bischof, 1994). Mellophones present with similar issues to a trumpet though pain is more likely produced, especially for those with smaller hands, in consideration of the instrument weight differences (J. Erdman, personal communication, December 5, 2014).

Tubas (also termed "contrabass") develop their own set of unique challenges because of the large size and playing method of the instrument. Some tubas used in drum corps are upward of 40 pounds placing stress on the forearms when holding the instrument in front or to the side of the body for long durations "at rest" (R. Marquis, personal communication, November 18, 2014.) Nerve compression pathologies and fatigue are 
stemmed from the body's inability to adapt to such weight demands (Dick et al., 2013). When playing, the tuba is placed on the left shoulder creating increased tension of the scalene, trapezius, deltoid, and latissimus dorsi muscles. Obstruction of view from the instrument increases the chance of collision with other members, potentially creating injury for either person involved.

Medical issues specific to percussion. Percussionists (or "battery") require refined precision and skill within the carpal bones of the wrist as well as the metacarpals and phalanges of the hand. Carpal tunnel syndrome in addition to wrist or arm tendonitis poses a potential problem with excessive playing (E. Hampton, personal communication, January 12, 2015). Carpal tunnel syndrome is especially prominent in front ensemble and snare players due to their technique; though mallet players have increased susceptibility because of the inability of harder surfaces to absorb vibration (E. Hampton, personal communication, January 12,2015$)$. Oversqueezing the drumstick relates to the subsequent impact transferred through each stroke; therefore, a looser technique is preferred in order to lessen such forces on the smaller hand bones (M. Mastriforte, personal communication, November 14, 2014). Furthermore, some snare players develop pain along the distal head of the ulna and flexor carpi ulnaris muscle due to constant flexion and adduction of the wrist (E. Hampton, personal communication, January 12, 2015).

Drum harnesses (inclusive of quads, snares, and basses) introduce the possibility of back pain (M. Mastriforte, November 14, 2014). The inherent load bears down on the spinal cord causing extra tensile pressure in the lumbar musculature and vertebrae 
(Siegle, 2015). Furthermore, the placement of a harness on the shoulders increases pressure on the deltoids, trapezius, and anterior structures (Dick et al., 2013). Like tuba players, it can cause compression of the scapular, brachial, or axillary nerves that turn into difficult nerve pathologies (Dick et al., 2013). Muscles of the neck (scalenes, sternocleidomastoid, levator scapulae) along with cervical vertebrae become strained to keep postural efforts upright (M. Mastriforte, personal communication, November 14, 2014). Quads and larger bass drum players tend to compensate for the weight distribution causing poor posture, which may magnify into lordosis or other issues of the spine (M. Mastriforte, personal communication, November 14, 2014).

Percussionists are also at risk for lower extremity injuries stemming from the difference in marching technique. Instead of a traditional forward and backward motion with slides to the left and right, percussionists must crab step in order to keep the drum flat to the sideline. The hips are kept parallel to the sideline while crossing one foot over the other allowing for lateral movement (M. Mastriforte, personal communication, November 14, 2014). Often, this motion will translate into knee pain, calf strains, patellar and Achilles tendonitis as well as hip dysfunction (Dick et al., 2013). In many instances, percussionists are unable to see below the drum for potential obstacles or holes on the field in addition to how their technique is being executed (M. Mastriforte, personal communication, November 14, 2014).

Though front ensemble (also know as "pit") members move minimally compared to the battery, it is still possible to accrue injuries. The main ailment stems from friction of the mallet grip causing hyperkeratotic lesions on the palm of each hand (Bischof, 1994). 
Due to location of where the end of a mallet rests, increased stress is placed on the third metacarpophalangeal joint (E. Hampton, personal communication, January 12, 2015). If open sores are left untreated, infection is a primary concern (Bischof, 1994). The dexterity and strength of phalanges IV and V are lacking in comparison to I, II, and III causing weakness or numbness in these two fingers with the first few weeks of heavy playing (E. Hampton, personal communication, January 12, 2015).

Medical issues specific to color guard/dancers. Statistically speaking, professional classical ballet and modern dance report high injury rates of $67-95 \%$ per year and approximately 1.7-6.7 injuries per dancer per contract year (Dick et al., 2013). More applicable to this thesis, Russell and Wang (2012) stated that $80 \%$ of the college student participants in their study reported at least one dance injury in their career that required missing one or more classes, rehearsals, or performances. The lower extremity is more commonly injured as a result of dance (Russell, 2013).

Russell and Wang (2012) further analyzed injuries by body part and found 59\% of participants sustained an ankle injury and $48 \%$ sustained a knee injury respectively. Poor footwear or dancing on hard, unforgiving surfaces commonly leads to such injuries (Magee, Manske, Zachazewski, Quillen, 2011). Although dancers and color guard members, in theory, should require supportive footwear to embrace extreme movement patterns, range of motion becomes limited without pliable material. These individuals consistently move from full forced dorsiflexion to full forced plantar flexion causing severe ankle sprains and impingements (Russell, 2011). Further proximal in the kinetic chain, general hip pain or internal snapping hip are unique to this population in 
accordance with forced turnout and exaggerated body movements (Russell, 2011). Jumps and leaps that are landed incorrectly (such as sauté or grand jété) may also increase chance of acute injury (C. Sheehan, personal communication, January 12, 2015).

Overuse injuries remain the most prevalent type of injury among dancers and color guard with highest incidence occurring in the foot, ankle, hip, spine, knee, and leg (Dick et al., 2013). For the foot and ankle, overpronation of the feet and hyperflexion of the toes in stance force strain within these structures (Magee et al., 2011). Hyperextension of the back is another common tendency that can lead to more serious conditions such as lordosis (Magee et al., 2011). In regard to the knee, many amateur dancers make technique errors such as failing to keep their heels on the floor in plié and not keeping the knee over the second toe (Magee et al., 2011). One study showed that $72 \%$ of dancers performed through pain associated with injury and planned to dance through pain in the future (Russell, 2012).

As shown above, dancers and color guard members often possess a "push through the pain" mentality, further inhibiting their ability to successfully heal from an injury. Psychological issues can also cause adverse effects physically and contribute to a higher injury rate (Dick et al., 2013). This population is known for wearing elaborate and sometimes revealing costumes or uniforms creating a certain expectation of appearance. Nutritional challenges and body image issues may be in part to the need of maintaining lean body physiques and optimal performance (Dick et al., 2013). Another unique complication seen among female members is the female athlete triad (Dick et al., 2013). This syndrome combines three physical deficiencies: energy depletion with or without 
disordered eating, menstrual lapses or amenorrhea, and decreased bone mass (Female Athlete Triad Coalition, n.d.). The energy deficiency imbalances the amount of energy consumed and the amount expended during exercise increasing the possibility for fainting, dizziness, fatigue, or confusion (Female Athlete Triad Coalition, n.d.). Additionally, a decrease in bone mass leads to weakened bones causing an increased risk of fractures (Female Athlete Triad Coalition, n.d.).

Not only are color guard members at risk of injury due to their bodily movements, but also with the equipment used. In drum corps, color guard synchronizes the spinning of rifles, sabres, and flags along with the music. Rifles are made of a combination of wood and metal with sabre and flag consisting of mostly metal except for the silk (C. Sheehan, personal communication, January 12, 2015). This causes a danger to the individual spinning the equipment, but also others around them if missed or caught incorrectly. A high toss (such as a 4 or 6 , meaning 4 or 6 rotations in the air) potentially decreases depth perception for the performer especially when moving (C. Sheehan, personal communication, January 12,2015$)$. As a result, the weapon or flag may hit the performer in the face or head putting them at risk for concussion, head injury, or facial laceration. Refined skill and technique is required to change and control a toss to the direction desired whether it be in front, behind, or toward either side of the performer (C. Sheehan, personal communication, January 12, 2015). Proper hand, shoulder, and arm technique are essential to ensure a clean catch and to avoid injury. Dependent on the repetitive nature of tossing and catching in addition to the velocity accumulated, equipment can 
create wounds and lacerations on the hands and fingers though protective gloves are worn (C. Sheehan, personal communication, January 12, 2015).

\section{Trust Between Athletic Trainers and Musical Performing Artists}

The National Athletic Trainers' Association (n.d.) defines athletic trainers as "health care professionals who collaborate with physicians to provide preventative services, emergency care, clinical diagnosis, therapeutic intervention, and rehabilitation of injuries and medical conditions for the physically active population." Certified athletic trainers have worked with the performing arts for over 25 years (National Athletic Trainers' Association, n.d.). Current job sources include work with well-known professional groups including Cirque du Soleil, Disney World and Disneyland, Radio Music Hall Rockettes, Cincinnati Ballet, and the Blue Man Group (National Athletic Trainers' Association, n.d.). Athletic trainers have the ability to demonstrate basic knowledge of intrinsic and extrinsic risk factors that could play a role in acute and repetitive use injuries in the musical performing arts (National Athletic Trainers' Association, n.d.). If trained and educated, athletic trainers have the ability to understand the musical performing arts not only in its physical demands, but the culture associated with the activity (National Athletic Trainers' Association, n.d.).

With understanding and knowledge of the art, athletic trainers would have the ability to explain the unique physiological and psychological impact of injury to performers (National Athletic Trainers' Association, n.d.). In a study conducted by Russell (2012), it was found that $54 \%$ of students disclosed negative experiences with health care providers (physicians, physical therapists, and chiropractors) due to lack of understanding of their 
activity (dance) or not spending enough time with them. Physicians and physical therapists have limited time available for large amounts of patients and also require appointments. Athletic trainers are easily accessible due to flexible working hours and being present at most practices and events if assigned to the specific activity. In addition to time, athletic trainers recognize risk factors pertaining to rehearsal, performance, and touring allowing for preventative techniques to be implemented (National Athletic Trainers' Association, n.d.).

Athletic trainers have extensive background in emergency care situations and are often the first to see and respond to an initial injury (National Athletic Trainers' Association, n.d.). For example, athletic trainers are well versed in the diagnosis and treatment of heat illnesses. By witnessing the mechanism of injury, an athletic trainer can critically evaluate the injury and approach it in a way that accommodates the performer. Often, this will take an alternate approach with quicker evaluation and creative treatment plans, but still encompasses the proper care of injury while also keeping the performer in activity if possible (Siegle, 2015). A patient-centered health care approach focuses on the personalization of care in respect of the patient's feelings, perspectives, and needs (David, 2013). If the individual feels as though their opinions and needs matter, trust can be built (David, 2013). Promoting trust through a patient-centered approach may also strengthen the patient-clinician relationship (David, 2013).

Through David's (2013) developed trust instrument, the factors of clinical competence, interaction, fidelity, and approachability most determined a patient's trust level with their athletic trainer in the collegiate setting. In addition, trust is more relevant 
to an athlete when an injury creates a perception of vulnerability (David, 2013). Athletes also noted that trust entails a sense of confidence in their athletic trainer (David, 2013). By incorporating and enhancing these aspects in everyday interactions, an athletic trainer should be able to facilitate a better patient-clinician relationship with musical performing artists.

\section{Conclusion}

The purpose of this chapter was to review the literature regarding trust and health care within the performing arts setting. The chapter also reviewed information on various performing arts with a focus on musical performing artists and drum corps. Specific medical injuries and conditions were analyzed among the three major sections in order to depict why athletic trainers are needed within this setting. By understanding a performer's unique needs, giving adequate time to patients as a medical professional, and striving for a patient-centered approach, trust can be built between athletic trainer and musical performing artist. 


\section{Chapter 3: Methodology}

This chapter reviews the methodology used to determine the factors of trust between the musical performing arts population and athletic trainers. With the performing arts representing a prosperous, yet underserved population within health care, it is essential for medical professionals to establish solid relationships with these individuals to provide the best care. This chapter describes the semi-structured interview protocol and sampling methods. Overall, the focus of this chapter is on research design, population of the study, data collection, procedures, and analysis.

\section{Research Design}

A qualitative semi-structured interview approach guided data collection through the use of Grounded Theory. This was an intentional methodological approach in order for the participants to create theory on trust and the patient-clinician relationship based on their experiences. Semi-structured interviews were chosen for the purpose of consistency of certain questions, but also to allow freedom of the participant to steer the interview in a direction best suited for their personality, feelings, and viewpoints. It also provided participants an opportunity to use thick description in their responses. Since David (2013) found favorable responses about trust using the Patient-AT Trust Instrument in the Division I collegiate athlete population, a similar interview approach and analysis was conducted.

\section{Population of the Study}

Participants were recruited from four drum and bugle corps $(n=12$, three per group; six female, six male). Each participant classified as a current World Class Drum Corps 
International member between the ages of 16-21 years old. Sample size was based on the assumption of saturation informed by the work of Guest et al. (2006), which suggested that 12 participants are usually needed for saturation to occur. Participants were recruited from lists of interested members provided by Head Athletic Trainers of World Class Drum and Bugle Corps. The researcher further contacted prospective participants via email or phone call after blind theoretical sampling (see Appendix A). The inclusion criterion was to have past interaction with an athletic trainer. Participants were excluded if they were first year members of the drum corps due to lack of interaction with a performing arts athletic trainer in this setting.

\section{Interview Protocol}

After obtaining IRB approval through San Jose State University (Protocol \#15215; see Appendix B), a semi-structured interview protocol was developed in order to guide each interview (see Appendix C). The interview questions were written and formulated based on the Patient-AT Trust Instrument developed by David (2013). The protocol also incorporated basic demographic questions (without identifiers) and questions specific to the musical performing arts setting. In addition, probing was used to better understand the responses of the participants (Patton, 2002).

Anticipated and spontaneous probes were incorporated into each interview. An anticipated probe included pre-identified follow-up questions while a spontaneous probe developed from questions as the interview took place (Willis, 2005). The semi-structured interview protocol employed the use of pre-determined questions in order to ensure consistency of the data collection. Spontaneous probes were used to further investigate 
the topic and allow participants to elaborate on any areas that became salient during the interview. Piloting took place through think-aloud interviews in which the researcher recorded answers and suggestions from five individuals associated with drum and bugle corps. After piloting the protocol, questions were refined based on the results to better evaluate the population studied.

\section{Establishing Academic Rigor}

To maintain trustworthiness of the research, credibility techniques of triangulation, member checks, external auditing, and connoisseurship were used (Creswell, 2000; Tashakkori \& Teddlie, 2010; Willis \& Jost, 2007). Each member of the research team worked together for triangulation to reach a consensus related to emergent findings. Member checks were conducted by having one-third of the participants examine their transcripts for accuracy (Creswell, 2000). Most participants were content with the original information provided in the interview. One participant expanded on her ideas for clarity when reviewing the transcript. External auditing assisted in verifying emergent factors of trust (Creswell, 2000). Any differences in opinion on codes or themes were discussed among the researchers until a final consensus was reached. The researcher previously worked within the setting of drum and bugle corps as an athletic trainer which created a layer of connoisseurship (Willis et al., 2007). Expertise in the content area allowed the ability to relate to participant experiences and colloquial language. Additionally, negative case analyses were examined for efficacy of the study (Tashakkori et al., 2010). 


\section{Procedures}

Upon start of the media connection, the participant completed the informed consent document (Appendix D), which was then e-mailed to the researcher. The researcher answered any additional questions prior to starting the interview. For participants under the age of 18, a parent/legal guardian was contacted via e-mail before the interview date in order to obtain consent for his or her child to participate in the study via parent/guardian consent form (Appendix E). If the parent consented, a participant child assent (Appendix F) form was also completed by the participant prior to the start of the interview. When the participant was ready, the primary investigator started the digital voice recorder and conducted the interview. Each interview took place over Skype in a quiet, private space and lasted approximately $22-56$ minutes $(\overline{\mathrm{x}}=36.5 \mathrm{~min})$ in length. At the completion of the interview, the researcher asked the participant if he or she had any additional questions. Contact information was gathered and his or her choice of desired gift card. The researcher later mailed a $\$ 25$ gift card to each participant as compensation for his or her time.

\section{Analysis}

Each interview was transcribed verbatim by a paid transcriptionist and then reviewed for clarity by the researcher to ensure accuracy. The transcripts were examined for patterns and themes by way of inductive content analysis (Pitney \& Parker, 2009). Inductive content analysis was used to discover recurring factors of trust throughout transcription without the hindrance of prior assumptions (Patton, 2002). The primary investigator coded the transcripts using Atlas.ti software by coding certain units of data 
that traced back to the research purpose and identified trust factors. An index of terms was classified and later categorized into trust factors to ensure organizational structure. Categories were based on regularity patterns and evaluated overall for divergence. 


\section{Chapter 4: Results and Discussion}

The purpose of this thesis was to determine factors that established or diminished trust between drum corps members and their athletic trainer. Prior to the study, the extent of trust established in the patient-clinician relationship in addition to the influences trust

had on those individuals were unknown. This chapter presents a profile of the participants along with a definition of trust as described by the drum corps members. Participant names and any other information that may impede confidentiality were changed. Lastly, details of the thematic analysis are discussed to address emergent themes in relation to existing literature on trust and the patient-clinician relationship.

\section{Participant Profile}

The following profile summarizes the backgrounds of the drum corps members involved in this study. By including this profile, the researcher adds depth to the reader's comprehension of participant diversity and characteristics these individuals represented within the drum corps community. It also gives a better understanding of where their perceptions of athletic trainers in the performing arts setting derived from.

The majority of participants (10 in total) were enrolled in college or had previously attended, while two of the participants were in high school. Several participants majored or planned to major in music education/music performance, although many studied other disciplines including biomedical sciences, hospitality, marketing, computer technology, and political science. Regardless of major, all participants were involved in the performing arts for years starting as early as the age of 5. In addition to drum corps, participants also mentioned their involvement in other performing circuits such as Winter 
Guard International (WGI), collegiate marching band, pep band, dance companies, and small music ensembles. All spoke highly of their passion toward music and performance and some even alluded to its ability to shape them into the individuals they have become.

At the time of data collection, the number of years participated in Drum Corps International ranged from one to three years ( $\overline{\mathrm{x}}=1.92$ years). Many participants completed a fourth year since then and a select few aspired to continue onto their fifth year in the activity. One participant described drum corps as "contagious," wanting to return season after season. Not only did participants attest to the musical and performing experience as motivation to continue, but also the friendships, travel opportunity, and the common goal of creating something "bigger than themselves."

Five of the participants resided in the South; four in the Midwest; two on the East Coast, and one on the West Coast. Several participants chose to commit to a corps far from their home state. Although drum corps is a traveling entity, each corps is based in a specific city and state generally causing that organization to spend a majority of their summer tour in that region. Participants explained some of the attributes factoring into the decision as follows: competition standards, corps traditions, music style, distinguished staff, and having friends who were veterans of that corps. Of the 12 participants, only three switched to different corps from year to year during their time in DCI. One participant moved from an Open Class corps to a World Class corps after gaining experience. The other two marched in a World Class corps and committed to a different World Class corps the following year. 
Interaction with athletic trainers in drum corps. The interaction between drum corps members and certified athletic trainers varied dependent on the number of athletic trainers available, how frequently the athletic trainers were sought out by members, and the general structure of how each corps integrated health care into their philosophy and schedule. On average, the participants interacted with two certified athletic trainers throughout their experiences in DCI. Many corps only had one athletic trainer available at a time, but some alternated between a few throughout the summer. When participants were asked how often they interacted with their athletic trainer during the summer tour, the answers were split. As reported by the participants, three of them approached the athletic trainer one to two times throughout the summer while two approached the athletic trainer infrequently. Joe recalled a negative experience with his athletic trainer admitting, "I tried to avoid the athletic trainer as much as possible." On the contrary, three individuals interacted with the athletic trainer frequently and four stated their use of athletic training services daily. Several participants, like Aubrey, described that seeing their athletic trainer became a regular part of the routine especially with overuse and long, repetitive days:

All our athletic trainers have done a really good job of being approachable. Obviously you're gonna be in pain, your body is gonna hurt. . . .If you start to feel something coming on it's easier for you to go and explain it and talk to an athletic trainer because they know what's best for your body.

Although not all participants used their athletic trainer the same amount, a unanimous agreement arose in favor of athletic trainers being on tour to care for drum corps members. To gauge perception of quality care, this interview question was asked of all participants: is there anyone besides your athletic trainer you would rather seek medical 
care from when you are on tour? All participants responded "no" with the exception of a few stating they liked to have the corps physician (if they had one) involved as necessary for the injury or condition. Additionally, several mentioned how the physicality of drum corps directly related to the general population targeted in athletic trainers' scope of practice. Emma described her thoughts on athletic trainers:

I think that athletic trainers are probably even more trained in the way that we need in drum corps than actual physicians are ... I think that as much as a physician knows they could probably apply the knowledge that they know to help you fix the problem, but athletic trainers are around that way more often. It would kind of be like asking a neurosurgeon to perform general surgery.

A common anecdote across the interviews was how awareness in the health care realm of the performing arts has slowly increased over the last few years. With growth in the activity, a shift has been made from traditional push through the pain mentality of 19801990s era drum corps to creating a safer, more modern approach to the marching arts (Bischof, 1994).

Participant injury history. Through interviewing, information was collected from the participants on injuries sustained during their drum corps experience. The number of self-reported injuries per individual ranged from one to four $(\bar{x}=2.1$ injuries); $65 \%$ of the injuries were lower extremity related and $35 \%$ were upper extremity related. As shown in Figure 1, the distribution of injury was predominantly acute with the remaining $40 \%$ divided equally between chronic injuries and general illness. Injuries reported by the participants (as diagnosed by the athletic trainers) included the following: shin splints, ACL tear, wrist tendonitis, ankle sprain, concussion, low back strain, patellar subluxation, hamstring strain, hip contusion, in-grown toenail, blisters, ankle ATF tear, 
MCL tear, knee sprain, groin strain, finger fracture, AC joint sprain, and facial laceration. General illnesses included eye infection, allergic reaction, bronchitis, tonsillitis, and ear infection. This information aligned with Bischof's (1994) epidemiology findings, though outdated, on a senior drum and bugle corps in relation to acute versus chronic injury rate. Each participant was asked to recall his or her most severe injury from drum corps and rate it on a pain scale from zero to ten with ten being the worst pain they have ever experienced. Pain level ranged from four to ten with 6.25 as the average.

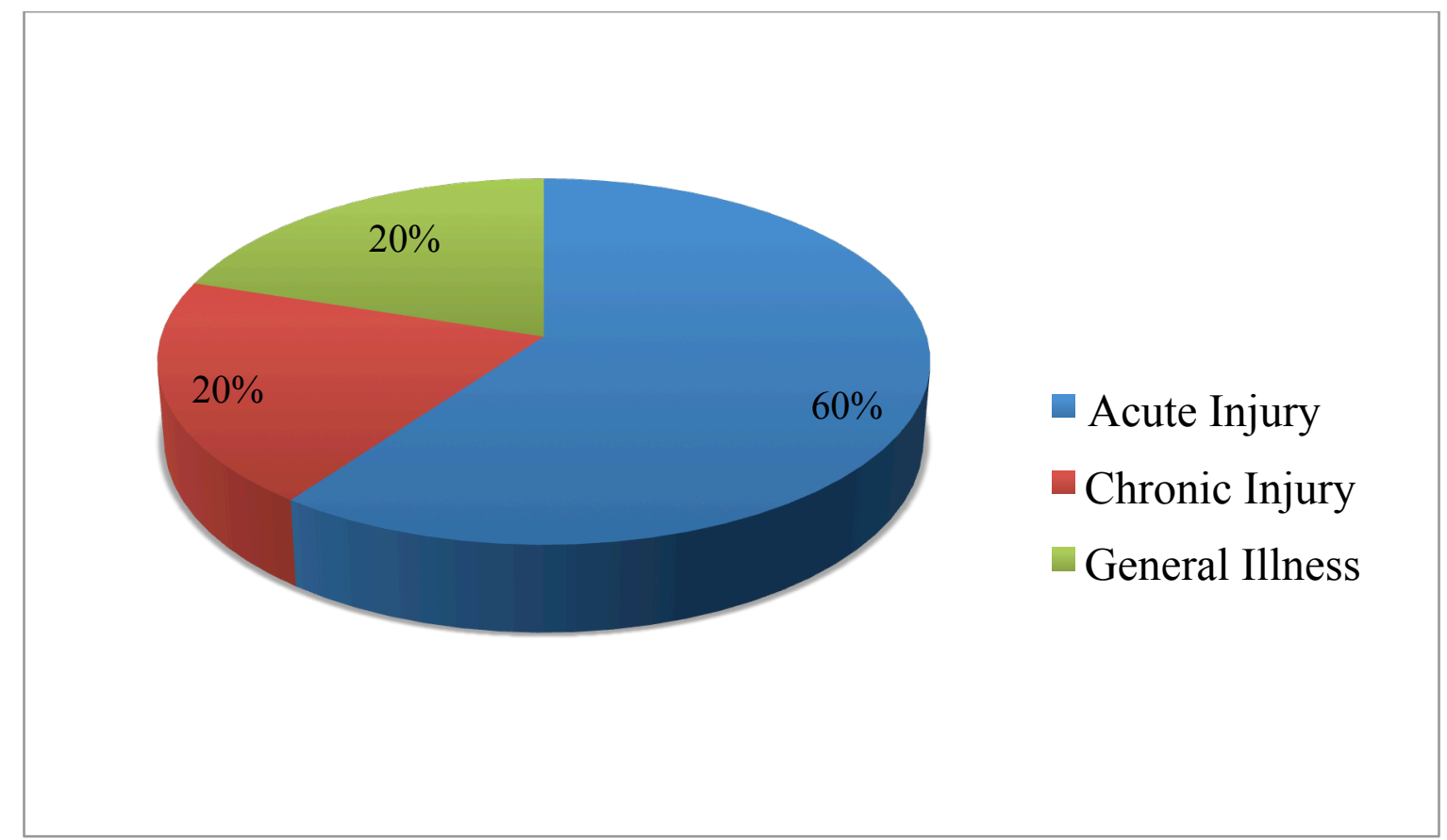

Figure 1. Drum corps participant incidence of injury.

As Dick et al. (2013) reiterated in his study, performing artists sustain injuries similar to those of traditional athletes due to complex movement patterns, overuse, and grueling environmental and scheduling demands. Participants in the present study reiterated this in their own explanations of injury rate in drum corps as compared to traditional sports. Matthew shared his opinion on the unique circumstances of drum corps: 
I'd have to say that there's probably more injuries per capita because the group for the most part is larger. They have 150 people on the field opposed to uh, soccer you have at most $20 \ldots$. I feel like drum corps rehearse much greater time even more than professional [sports] because it's Sunday through Saturday daylight to dusk, non-stop work and that just has inherent injuries involved with it and so I think it's hard to go through a season without something happening. Things will happen occasionally, but with drum corps it's almost a guarantee to have some moment where some part of your body decides it isn't gonna work for you anymore.

Several participants noted that although they did not believe drum corps injuries were as severe as those suffered by a soccer or football player, the sheer number of injuries developed was equivalent. The nature of contact in traditional sports was taken into account when discussing the differences in addition to specialized situations based on position or section. Charlie drew this parallel between the two populations: "It's the same possibility of getting injured in drum corps than it is in typical sports ... [our] injuries are from overusing muscles and not paying attention.” Overall, injury was viewed as an inevitable part of the activity. Participants did not assign a negative connotation or sense of weakness to the perception of injury. This attitude fostered an understanding of the physical stress required for drum corps and progression toward acceptance of limitations at times.

\section{Thematic Analysis}

The thematic analysis included organization of raw data themes by assigning labels to specific units of data that had meaning to the research purpose. Higher order themes were then identified and sorted into two general categories: professional proficiency and interpersonal dynamics. In the following sections, the general categories and subsequent 
emerging themes will be presented. Table 1 outlines the factors of trust as perceived by drum corps members through inductive content analysis. The number in parentheses next to each raw data theme signifies how many times that idea was referenced within the interview transcriptions. 
Table 1

Factors of Trust as Perceived by Drum Corps Members

\begin{tabular}{lll}
\hline Raw Data Themes & Higher Order Themes & General Categories \\
\hline $\begin{array}{l}\text { Professionalism (17) } \\
\text { Consistency (14) }\end{array}$ & Professional Traits & Professional Proficiency \\
$\begin{array}{l}\text { Promptness (return to play) (12) } \\
\text { Confidentiality (9) }\end{array}$ & & \\
Accessibility (42) & Availability & \\
Access to medical supplies (16) & \\
Clinical competence (30) & Clinical Credibility & \\
Plan of action (22) & \\
Personalization of care (16) & \\
$\begin{array}{l}\text { Reputation (15) } \\
\text { Clinical experience (14) }\end{array}$ & \\
Knowledge of drum corps (8) & & \\
& & \\
Comfort (22) & & \\
$\begin{array}{l}\text { Approachability (18) } \\
\text { Altruism (15) } \\
\text { Empathy (10) } \\
\text { Personal connection (8) }\end{array}$ & Personality Traits & \\
$\begin{array}{l}\text { Dependability (25) } \\
\text { Fidelity (8) }\end{array}$ & & \\
Communication (17) & & \\
\hline
\end{tabular}

Professional proficiency. The general category of professional proficiency referred to how well a clinician performs their job and demonstrates a level of competence in their skill set. This not only was attributed by upholding professional standards, but also in 
maintaining respectable work ethic. Three higher order themes emerged: (1) professional traits, (2) availability, and (3) clinical credibility.

Professional traits. Professionalism and athletic trainers holding their work as a clinician to a high standard was seen as a crucial element in participant trust. Since the relationship was built around participant health, it was clear professionalism held significant weight in the way participants were treated. Several participants stated that a correlation exists between the way the athletic trainers conduct themselves professionally and their ability to perform a medical procedure or evaluation correctly. Joe expanded on this connection: "I think professionalism speaks a lot about, um, how well they do their job. It's part of trust and if they're not being professional with their job, I don't know how I could trust them to do their job." A few of the participants noted that professionalism should be displayed, but not to a point where the athletic trainer was unapproachable or intimidating. The participants wanted to feel comfortable with their athletic trainer and have genuine interaction even though the situation may have been medically severe. Maria explained how these traits were incorporated into professionalism:

So, it's just kind of meet in the middle like, like a friendly interaction, but still like if they dress up for the events, like the shows and stuff, that shows you, that they are your 'friend' in a sense, but still of a higher authority and you know they have power to get things done.

Referring this idea back to studies by Barefoot et al. (1998) and Dwyer et al. (2012), the ability for the patients to talk with their doctor on a personal level was ranked as one of the most valuable attributes in the patient-clinician relationship. 
Along with professionalism, the participants described how consistency factored into their ability to trust the athletic trainer. This concept was twofold: (1) having consistent access to the same athletic trainers throughout the summer and (2) continuity of care. In terms of consistency through access to athletic trainers, participants recognized that having the same individuals throughout the summer allowed development for a professional and personal relationship with the athletic trainer. Emma elaborated positively toward consistency of athletic trainers in her drum corps:

I think personally one of the, the biggest things that had me, really trust the athletic [trainer] staff is consistency. So, we've had the same athletic trainer which I think is really helpful because all the veterans at least know the medical team. We know we can trust them and especially when new members like when they're freaking out about something, um, I think that they feel comforted knowing that we ... have been there a while and trust the medical team.

Some drum corps alternated between different athletic trainers (and other health care professionals) every few weeks instead of having the same medical staff all summer long.

Charlie expressed how he found this approach to be ineffective:

If someone new comes in and they have to do the whole like, 'oh I have to understand what you are going through right now' and it's gonna take a few days for them to actually like figure out exactly what like, what your pain level is and what you're, what you're struggling with.

In general, the participants appreciated having consistent medical staff which directly aligned with Ozawa and Sripad's (2013) association of patient trust being based on loyalty to a physician.

Moving toward continuity of care, participants discussed an expectation that the athletic trainer is consistent in their care for an injury through each encounter over time. Nathan shared his thoughts: "I've really described it [trust] as like, trusting someone as 
them knowing what they're doing and being consistent with what they do and I feel like that fits along with the [athletic] trainer role." It is interesting to note that participants were not only concerned that they receive continuity of care individually, but also that every injury and condition regardless of severity was treated with the same level of attention. One participant recalled suffering from a minor ankle sprain and appreciating the athletic trainers' attentiveness though other members were clearly working through significant injuries:

It was nice to be treated the same as the injuries that I knew were worse 'cause I was like, 'oh man, I hope they don't think less of me 'cause...' Sometimes I would think it sounds like complaining then I like look back on it and, 'oh yeah, I couldn't have gone without getting help from the athletic trainers.'

This ability to treat all drum corps members and their subsequent injuries with fairness and objectivity corresponded with Borum's statement (2010) about integrity as a health care professional. By promoting integrity in the skill set as an athletic trainer, the drum corps member perceived dedication toward their injury status and general well being, therefore, instilling trust.

Another aspect relating to professional traits was promptness. For the purpose of this thesis, promptness was articulated by participants in reference to the athletic trainer's ability to respond quickly to an injury scenario or provide timely return-to-play for an injury. Not all participants had positive outcomes in this area, however, a general agreement was made that promptness played a role in their success on the field. Emma described how the shift in having medical staff as a part of the organization had decreased the amount of missed rehearsal and show time due to injury: 
Instead of having to take [the member] somewhere or whatever they know that the medical team can kind of just do everything on-site quickly which is really helpful. Especially when we didn't have an athletic trainer or physician . . . we always had to take you out of rehearsal and drive you to a place to get your injury looked at ... And you would miss a lot of rehearsal time, whereas now, if you have athletic trainers on staff, constantly, you're able to solve those problems a lot more quickly.

Another participant, Aubrey, deemed promptness as one of the more important qualities in trusting her athletic trainer by stating, "If they got called in they would be there as soon as they could so that just shows a lot of initiative and a lot of consistency with what they said." Due to the demands of drum corps and detriment caused to the production as a whole by a member missing rehearsal time, participants encouraged a sense of urgency. Of course, athletic trainers should handle situations in the standard of care that best suits the medical issue at hand, however, swift return-to-play and timely sideline evaluation created sufficient flow for the needs of DCI.

The last professional trait mentioned by participants was confidentiality. It was fairly surprising to find that many participants were not as concerned with this trait compared to other work-related components. In a systematic review on patient perspectives of medical confidentiality, the majority of studies concluded an overarching belief that sharing and access of medical information should be restricted to those involved in patient care (Sankar, Mora, Merz, and Jones, 2003). On the contrary, several drum corps participants felt comfortable with information being shared with other staff members as necessary. A potential reason for this altered view could have been the nature of activity. Drum corps is unique in the interactions created between members and staff. Three months are spent together, 24/7 while touring, which establishes strong bonds and interpersonal 
relationships. This could attribute to the drum corps member trusting information to be passed along multiple areas of staff: administration, medical, instructional, and so on. Additionally, health conditions and injuries can directly affect physical and technical production on the field. A high standard of performance is always expected and staff/judges meticulously critique small discrepancies in drill or movement patterns. By allowing the discussion of medical information openly with instructional staff, a member's visual inconsistencies and alterations in musical playing ability or equipment tosses can be permissible based on injury limitations. In alignment with the literature, participants may not have fully understood the standards medical professionals must abide by as well as clinicians' legal or ethical rights associated with medical confidentiality (Sankar et al., 2003). This lack of knowledge generally leads to underestimation of confidentiality protections (Sankar et al., 2003).

The way the athletic trainer maintained confidentiality linked back to establishing a level of trust in addition to being viewed as professional: "My athletic trainer was trustworthy by keeping secrets. That's totally cliché, but they take my health in confidence and keep it in confidence unless given permission otherwise. I liked how they stayed professional in a somewhat unprofessional setting." Although different per participant, confidentiality developed as a less prominent theme.

Availability. Availability was the most prominent theme in the matter of frequency within the transcripts (see Table 1). This term encompassed the participants' ability to access an athletic trainer and medical supplies while partaking in drum corps. With medical care being new to Drum Corps International and the realm of performing arts, 
many participants paralleled the positive impact of merely having a health care professional available to them. It also facilitated a positive shift in trust, as determined by participants, due to the ability to approach an athletic trainer on the sidelines directly after mechanism of injury. In general, the more visibility an athletic trainer had with participants increased a sense of safety or comfort, thus, instilling trust.

In the interviews, the researcher asked if the participants had consistent access to an athletic trainer throughout the duration of their drum corps experience and if so, how often the athletic trainer was available. The responses were as follows: six participants stated "all the time," two stated "some of the summer," and four stated some years they had access and others they did not or had another health care professional instead (nurse, chiropractor, massage therapist, etc.). Although the majority had access to athletic trainers all summer long, many stated a need for more clinicians. Charlie commented: "I do think that more athletic trainers, like a better ratio of athletic trainers to members, that would make it easier for more people to get the medical attention that they needed at the time, especially at spring training." Emma added a note about the size of the corps, "We're kind of like understaffed in terms of athletic trainers in my opinion because you have 150 plus drum corps members trying to talk to the same two people." In a typical athletic training setting with large scale sports like football, athletes have access to at least two or more certified athletic trainers in addition to extra part-time staff such as interns or students (National Athletic Trainers' Association, 2007).

With access to one or two athletic trainers, workload is high especially with limited amount of time allotted for duties such as taping, injury evaluation, medication dispersal, 
and rehabilitation. This does not account for the time also needed for documentation, restocking or loading of supplies, and communication with parents and the corps physician. As detailed by the Recommendations and Guidelines for Appropriate Medical Coverage of Intercollegiate Athletics (2007), many factors are involved when determining the number of athletic trainers needed for a sport's health care coverage. A few of these include injury rate (both time-loss and non-time loss injury), required time for treatment or rehabilitation, potential for injury based on amount of exposures, and travel requirements (National Athletic Trainers' Association, 2007). A numerical calculation was devised in order to clearly establish the appropriate number of certified athletic trainers required for each sport specific to its demands (National Athletic Trainers' Association, 2007). It was found that one full-time certified athletic trainer should be responsible for no more than 12 health care units (e.g. If a college has 48 total health care units, then the institution should have the equivalent of four full-time certified athletic trainers; 48 health care units divided by 12 health care units per athletic trainer $=$ four full-time certified athletic trainers) (National Athletic Trainers' Association, 2007). As shown in Table 2, drum corps is estimated to require roughly the same medical coverage as football. Although these numbers would fluctuate based on the corps, the numbers provide a fair representation of the population need.

The participants also discussed lack of sufficient time with athletic trainers. Amy explained her circumstance:

That would kind of be the only reason I wouldn't go talk to an athletic trainer, if I had a problem, would be because I just didn't have time or there wasn't one. They were just busy with other people the time that I had available. 


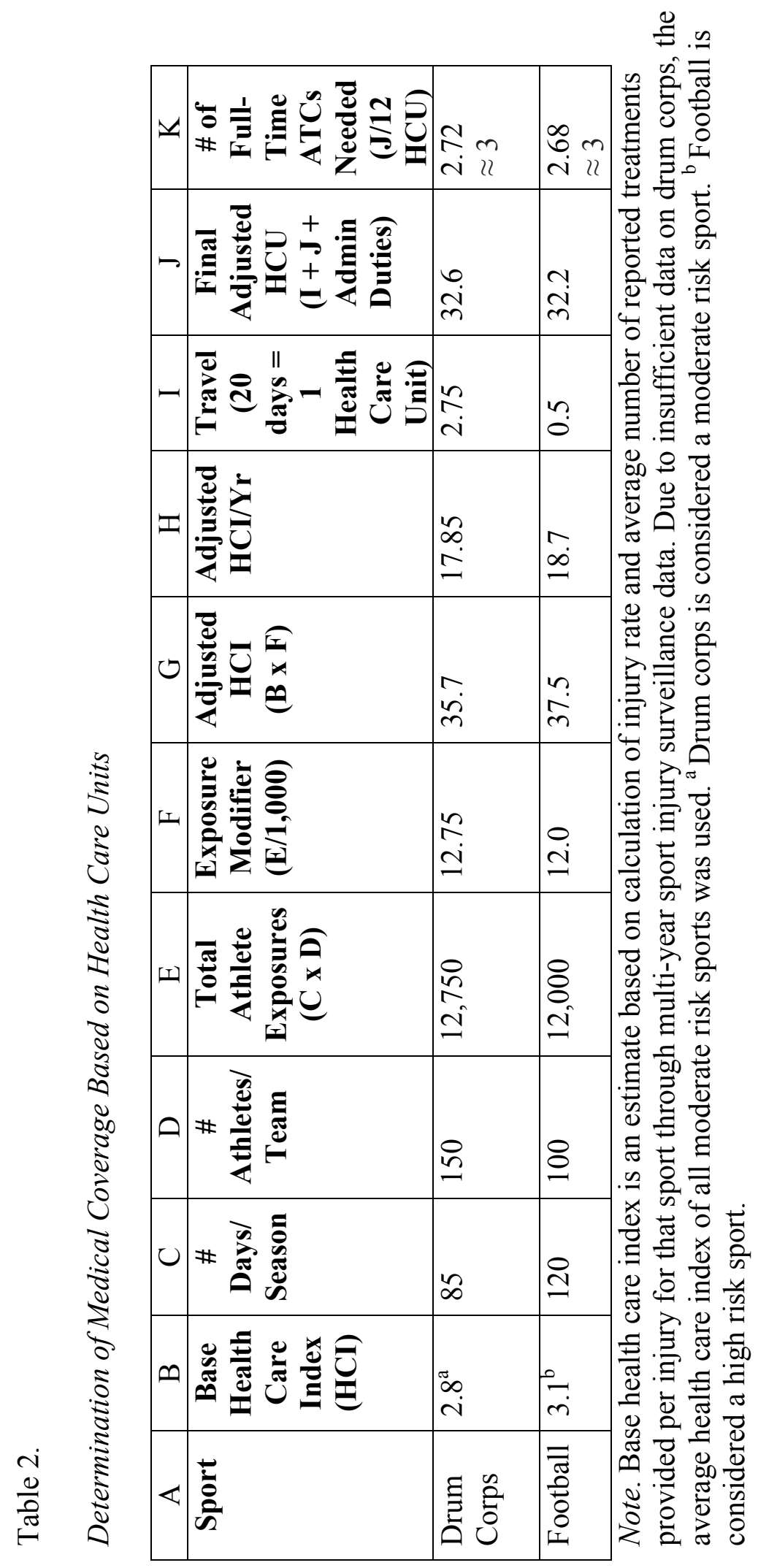


In drum corps, members typically have one-hour meal blocks in between rehearsals in which they can discuss issues with the athletic trainer. Otherwise, there may be minimal free time before traveling or at the end of a day, but is dependent on scheduling. As a general rule, the athletic trainer only interacted with members during a rehearsal or show if an injury occurred that impeded their ability to perform. This means the athletic trainer must be proficient with time given to care for members.

To help combat time constraint, athletic trainers introduced prevention strategies in order to decrease potential injuries. Nathan remarked how prevention assisted his ability to manage time needed with the athletic training staff, "I think that, um, athletic trainers who are active and like helping us understand when something is hurting and what to do about it affects whatever strain intense exercise is going to have on us." Regardless of how well prepared an individual was, injuries were inevitable. The majority of participants agreed that the strenuous nature of drum corps validated the reason for access to an athletic trainer on tour. Emma reiterated the stress of drum corps on the body:

It's such a strenuous activity especially because you're, at least as move-ins, you're rehearsing 12 hours everyday which is really hard on your body especially if you haven't been conditioning well which most people don't condition well ... just the fact of jumping into a 12 hour rehearsal schedule where you're constantly moving around and having to stop constantly in between things.

Some participants, like Patrick, even attested to the thought of not being able to march through the summer without access to an athletic trainer: "I needed to have an athletic trainer on hand otherwise it would've been just as bad as the person who would have been marching in my spot [had I been replaced].” These statements follow Dick's et al. (2013) observation outlining the performing arts as a high-risk, underserved population. 
Coinciding with access to athletic trainers, participants talked about the need for proper medical supplies. Though solely dependent on funding from each drum corps, athletic trainers can only be successful in the confines of the supplies or tools provided for them. Natalie discussed the recent change in mentality toward medical needs:

I think people are realizing more now that there are a lot of things that can go wrong in drum corps so for example we had like a box of Band-Aids and like Neosporin . . . but we didn't have any actual like medical equipment and then once we got our athletic trainer on tour with us, um I think they started realizing people need more than to just slap on a Band-Aid.

Matthew spoke to the odd predicament of how the organization is run and the challenges it presented to proper health care: "I mean it's like a traveling circus or a band of gypsies really. There's only so much you can stock with that type of environment. I felt that they had everything for the type of injuries commonly seen." Without the ability to store supplies in a stationary room, athletic trainers face difficulty of organizing all supplies in travel-ready kits and totes in anticipation of moving constantly. There is also limited amount of space under busses or on equipment trucks making it crucial to pack only what is needed.

Overall, participants expressed gratitude toward the resources (staffing and supplies) available to them in drum corps, but foresee a need for progression toward larger medical staffs and specialized supplies in order to be taken care of sufficiently with all injuries acquired on tour. Participants displayed more trust in their athletic trainer whom had the appropriate medical supplies to care for their injury or condition at hand.

Clinical Credibility. Morgan (2012) defined clinical credibility as the ability to apply theory to practice and doing so in a manner of personal integrity. The elements comprised 
within this higher order theme were clinical competence, clinical experience, having a plan of action, personalization of care, reputation, and knowledge of drum corps. It was found that the athletic trainers who exemplified these elements within their everyday work were perceived as more trustworthy to participants.

In account of all raw data themes, clinical competence was coded the second most frequent. Interestingly enough, David's (2013) study on Division I collegiate athletes' trust in their athletic trainer also revealed clinical competence as the second most reoccurring code within the data. This theme portrayed the ability for an athletic trainer to perform their job well. Generally, most participants were satisfied in their athletic trainers' ability to care for injuries as stated by Patrick, "the problem that I had was handled very well and it had a huge impact on my ability to perform correctly," and Aubrey, "they know what they're doing in their craft and everything." Participants had several ways of determining whether an athletic trainer was clinically competent by assessing articulation of knowledge and use of medical expertise to best care for their needs as a drum corps member. Emma addressed the implications of articulating medical information well:

Being able to ask them something or being able to ask for their help in something and know that things they're telling you or the advice that they're giving you is valid and has some kind of backing. As opposed to just like people who you would ask them for help and they just kind of tell you the first thing that comes to mind because they don't really know what they're talking about.

Later in the interview, she continued to state: "They have to be knowledgeable about whatever they're talking about or at least if they're not knowledgeable be straight forward about it, then go find out ... or whatever the case may be." An athletic trainer 
being honest about their knowledge base and as thorough as possible, but also admitting when he or she was unsure increased clinical credibility among participants.

Along with articulation of knowledge was the ability to use medical expertise for the greater good of the participant. Luke succinctly stated, "It's important to me to trust that the medical provider is both competent in their field and looking out for my health." By proving to a participant that his or her well-being was of utmost importance added a layer of trust.

In addition to clinical competence, clinical experience played a role into trusting an athletic trainer. Olivia spoke directly in reference to drum corps athletic trainers, "I don't think like a lot of people would imagine you like get injured in marching band type things, like I think that having a previous knowledge and experience would help." Another participant, Patrick, explained that he felt athletic trainers' experiences in athletics would help build trust regardless of prior work with drum corps, "I felt that I could trust them based on their experience working with other groups." Patrick noted his reluctance toward an athletic trainer who had not previously held a job within the medical field adding, "amount of experience directly feeds into credibility."

Participants preferred their athletic trainers to be proactive and create a plan of action when injured. Luke emphasized that not only was it helpful to have a medical professional available, but "always having somebody there that was able to, if not completely solve the problem, having an approach as to how the problem could [emphasis added] be solved." Many participants found follow up to be a crucial part of 
their success in healing. Natalie divulged into a story about her experience overcoming a knee injury:

He kind of like assured me, 'you know if you do this and you come see me and we like, help you stretch your hamstring out and work with your MCL and your ACL, you know that you'll hopefully get better by the end of the season' and I did.

Though Joe experienced more negative encounters with athletic trainers, he drew back to an earlier season where he made this observation: "Follow through on something you say is a big thing for me. I think that actions speak louder than words and someone's actions really define who they are as a person and how much I can trust them." Similar to Caterinicchio's testament (1979) about consistent positive treatment outcomes increasing trust and loyalty of a patient, having continuous positive outcomes from a plan of action or injury progression attributed to drum corps members' trust.

In congruence with plan of action comes personalization of care. This concept accounted for a member's feelings, perspectives, and needs. As shown through David's dissertation (2013), personalization of care cultivates trust, therefore, laying a framework for the patient-clinician relationship. Over half the participants listed out situations or examples where athletic trainers personalized their injury care to better suit them individually. Emma appreciated the athletic trainers taking in account her mobility needs in her hand and wrist for catches as a color guard member:

I know sometimes we have a lot of weird requests where, well our wrist will be hurting, but it still has to be mobile 'cause you'll have to be able to use your wrist and so sometimes especially with like taping ... I had some like wrist pain and we tried to tape it, but it was too stiff and I couldn't move it and so, we had to kind of regroup and figure something else out. 
Olivia, a brass member, acknowledged their approach in caring for her back injury dependent on what was expected of her in rehearsal that day:

My athletic trainer understands that I need full range of motion of my body. I would get KT tape if I had to be in rehearsal or doing visual exercises so that my body movement isn't restrained, but then I was given different things like, heating pads or ice packs when I didn't have be moving.

Lastly in the theme of clinical credibility were the aspects of reputation and knowledge of drum corps. In the culture of drum corps, reputation highly influenced a member's perception of an individual. Members had tight bonds with one another causing a ripple effect when information (whether negative or positive) was passed along from person to person. Matthew further explained this phenomenon: "There comes a point where they can change your perception (snaps finger) like that so if the corps decided to round up against them I can't see that they'd be able to get themselves out of that." When athletic trainers did not respond in a manner that Joe felt fitting for the situation at hand, reputation was altered creating a shift in his ability to trust them:

A few years ago when we had the illness outbreak across the corps, there were a lot of people who, um, had gotten it and were quarantined who had mentioned like how the athletic trainers had treated them or talked down to them or um, how they weren't professional about handling the situation. They had spoken poorly about the athletic trainers based on their experiences and that has affected my views of the athletic trainers.

Reputation did not always stop participants from seeking care especially when in dire need of medical attention, but created a sense of caution and changed perception.

Though not a "requirement," participants respected athletic trainers with a prior knowledge of drum corps since it demonstrated a general understanding of the activity. Luke informed that it might assist the athletic trainer in injury awareness: 
I think that drum corps injuries sort of take a trained eye to spot. So somebody who has been around the activity longer could, you know, recognize something like a shin splint in a tenor's crab stepping technique or development of tendonitis due to a color guard member's repetitive five toss ... so I think the more experienced drum corps medical staff are probably the better at spotting those conditions and medical problems.

Additionally, Olivia suggested a basic background in music facilitated an easier transition for the athletic trainer:

One athletic trainer did it the previous year so he had some basic knowledge ... that was [another athletic trainer's] first year ever seeing a drum corps, let alone even a marching band and she was almost like, shocked of how, you know, how much they push us and how strenuous it would get.

Like any sport, a general knowledge of scoring, rules, equipment used, and basic terminology allows an athletic trainer to enhance their care for the specific athletic population worked with.

Interpersonal dynamics. Interpersonal dynamics, as a general category, referred to attributes that helped develop a bond between two people and a clinician's ability to interact with a patient. Three higher order themes emerged including: (1) personality traits, (2) advocacy, and (3) interaction.

Personality traits. Beyond professional traits, there were attributes of an athletic trainer's behavior that participants claimed as "personality traits" or elements that built into the individual's character. Comfort, a state of physical ease, reigned as one of the more prominent traits in participants' opinion. A common anecdote about comfort was stated as "allowing the walls to come down" and giving control to the clinician in order for them to help the participant. Aubrey magnified this idea: "I'm trusting you ... then that means the control is out of my hands, but it's in yours and I'm letting you take over. 
So, it means that I'm comfortable with someone else having control." Matthew paralleled a similar statement by saying, "in any number of ways making you able to share a certain aspect of yourself with another person and not feel threatened in doing so."

Comfort paired with an aspect of vulnerability. This fostered into opening up to someone when in need, but having confidence in the clinician's ability to care for them. Olivia confided a memory in which the athletic trainer proved her trustworthiness:

I had my first panic attack ... I [didn't] feel, like, rehearsal capable at the time and I didn't really know that it was my first time ... but I didn't go to her after it happened because I didn't know if that was like something I should do ... I remember like she came up to me anyway because I think a tech told her to and I was kind of iffy and didn't know if she would understand the situation or if I wanted to talk to her about it, but I know it was the first time I trusted her because she sat down and made the effort. She was calm and collected and made sure I was okay.

Several participants described comfort in terms of being easy-going. This sense of ease alleviated any anxiousness with health related concerns. Matthew detailed an example of how his athletic trainers used this tactic:

When they were helping even treating you they ... didn't focus on 'oh man, your leg's bleeding, that sucks.' They were trying to take your mind off it and were good about just being conversationalists and keeping you from thinking about 'oh I just got smacked in the head by a contra and I can't remember the last 20 minutes of my life.' So, yeah. They were, they were good people. Good to work with.

Without comfort, a patient will become uptight or nervous impeding the ability for the athletic trainer to help them adequately (Borum, 2010). In the same vein as comfort, participants noted importance in the athletic trainer being approachable. Maria stated, "I definitely think that the athletic trainers need to be approachable and have a positive 
attitude about anything." Emma also mentioned how the athletic trainers developed a friendly demeanor in their approach creating a sense of security:

I think all our athletic trainers have done a really good job of being approachable ... I don't think anyone is afraid to approach them and I've gotten to know them over the years, kind of like going to a friend and being like, 'hey, my body hurts.'

Comfort and approachability were traits participants' believed directly linked to a practice of altruism.

Altruism, defined as the "willingness to act in the interests of other persons without the need of ulterior motives," (p. 249) factored into trusting a clinician's intentions (Steinberg, 2010). Luke prompted his response by stressing the athletic trainer's altered mindset on his circumstance that would not be present among other staff members:

So, the night I had to have my in-grown toenail removed, there was supposed to be a full run of the show the night before the big regional and the athletic trainer could have told me that I'm going to do the procedure, but you need to be back on the field for the full run. Which is what the mindset of the instructional staff would have been, but she told me that it's probably best that you take the rep off and don't do the full run and I took that advice really to heart, you know, thinking that this person is looking out for me specifically as opposed to just the drum corps. My health is what is coming first.

Olivia added how athletic trainers took into account the essence of performances and ensuring drum corps members were fit to do so in the whatever way possible:

My athletic trainers know that being in the show every night is like, one of the most important things. Especially, like when you're touring ... that's why you go to rehearsal and everything... So they helped so that I'm able to do my best and get into every show.

Emma smiled and concluded, "I know no matter what happens during the day, if it's like hot or crazy or something, I know that the athletic trainers are going to be there to help you." These stories support the literature though the term benevolence was used instead 
of altruism. Borum (2010) described benevolence based on the perception of a clinician upholding goodwill and a sense of care.

In addition to physical challenges in drum corps, mental stability also became tough at times. Participants desired empathy as a means of handling certain instances. Charlie and Matthew referred to the method of active listening. Charlie explains, "you have to trust that your athletic trainers are there to listen when you're stressed, when you're freaking out and you have to trust that they are gonna calm you down from that." Matthew added, "the ability to, you know, they're gonna be quiet and nod along and being a person to talk to." Beyond active listening, Nathan stated the effort (or lack thereof) in understanding how he felt did not go unnoticed. It was noteworthy that only males directly referenced empathy in their interviews, whereas, female participants did not. Although gender differences on importance of empathy is argued within the literature, several sources claim that females demonstrate empathy more than men and desire it at a higher rate within relationships (Hojat et al., 2002; Schulte-Ruther, Markowtisch, Shah, Fink, and Piefke, 2008).

In the study conducted by Schulte-Ruther et al. (2008), neuroimaging (fMRI) was used to track brain pathways and neural activity in relation to empathy. Females were found to present with stronger emotional resonance, while males exhibited a more cognitively driven and distant approach to emotion. According to the study, a typical female brain empathized superiorly over systemizing capabilities, in which, male brains showed the opposite pattern (Schulte-Ruther et al., 2008). The drum corps participants 
diverged from the findings within this literature; however, empathy has been found to hold importance in the patient-clinician relationship regardless of gender (Borum, 2010).

Although a personal connection with the athletic trainer was a determinant of relationship rather than a personality trait, all preceding personality traits in this section helped to build (or hinder) this connection. Maria illustrated this concept best with an analogy:

Trust is when you can put your whole self into someone else and they're reliable, um, it's just about reliability and about connecting with another person or another unit and being able to lay all of your work out there and have it be protected in this little (pause) trust is like a big protective shell. You know, um, it's a big protective shell that like connects you or another [human] being and I don't know it's just like, this bond you know. 'Cause you know, if you break trust, if you break someone's trust then you break the shell.

Similar to reputation, establishing personal connection with each individual seemed to "make or break" a drum corps member's ability to form loyalty with a clinician.

Advocacy. Advocacy entailed two separate facets: dependability and fidelity. Dependability was in reference to being counted or relied upon whereas fidelity represented faithfulness to a person through demonstration of continued support and loyalty (Dwyer et al., 2012). Luke proposed the significance of dependability within health care, "If there is trust built around anything, it's through the preservation of your own body so I think that having somebody that you could depend on for medical reasons, you can depend on for most reasons." Emma shared her feelings on how it should be commonplace to depend on athletic trainers because they were hired for that purpose:

We trust the professionals and we're more than willing to go to them for any reason if we ever need to as opposed to just trying to solve the problem on our own. I think, if you trust the person, you are more willing to go to them because you know that whatever they tell you is a better bet than what you are going to 
find on the Internet. I would trust her [my athletic trainer] with my life and I have pretty much.

On a separate spectrum, Nathan and Matthew said it was almost a forced dependability due to the athletic trainer being the only medical professional they had access to all summer. When asked whether or not he felt he could depend on his athletic trainers Nathan retorted, "um yeah, but it was mostly due to like circumstance. Who else are you going to go to?" Matthew admitted unfamiliarity with the scope of practice of athletic trainers prior to their presence. This resulted in hesitancy toward trusting athletic trainers:

Not knowing anything about the field I kinda didn't have a choice so I don't know if I ever trusted them in like, 'I know that you know this,' it was more of 'I really hope you know what you're talking about' because I need you to.

Dependability, whether earned or forced, provided consistency for the participants and at the very least a mindset that someone would be there to care for them if the need arose.

As found in other studies (David, 2013; Dwyer et al., 2012), fidelity facilitated trust in the patient-clinician relationship. This concept was in relation to putting the patients' health above other concerns when making decisions of their behalf (Dwyer et al., 2012). Fidelity is thought to be fulfilled if the clinician demands care that the patient would have chosen if he or she had the same expertise and information available (Dwyer et al., 2012). Aubrey affirmed this through her personal experiences:

Somebody that has faith and trust put into them and is able to return it, like with the medical staff, where I put my trust into them hoping they would be able to help me get back on the field as quickly as possible. And they returned that trust which makes them more trustworthy.

Fidelity built a sense of advocacy and promoted focus on the patient as a whole opposed to specific problems that were presented (Hall et al., 2001). 
Interaction. This theme included two properties that influenced trust concurrently: communication and collaboration. Comments were not only centralized around interpersonal communication, but also the medical staff's capacity to communicate on the participants' behalf. Matthew described how communication bridges a gap in the patientclinician relationship, "Trust is more just the ability to converse with somebody and (pause) open up in any number of ways." For several participants, communication tied back into clinical competence. Charlie defined communication as an evaluation tool, “'Well, why does your leg hurt? Where does it hurt?' It's a lot of trying to figure things out and you have to work together to be able to do that." Maria stated that communication provided reassurance, "I think it's being able to have them say something every time. Something helpful every time that I came to them and they can take away my fears or praise my progress so the trustworthiness is there."

As for interaction with other staff members, participants liked having athletic trainers as advocates for their injuries by means of communication. Olivia explained a time where she relied on her athletic trainer for assistance:

Yeah, it's nice ... to legitimize, if you have an injury or legitimizes a reason that you can be sitting out, it's like they know you need someone who can also be like a voice to someone higher up because sometimes we are not always taken seriously.

Natalie discussed how crucial communication was in her experience with a concussion on tour: "With my concussion, I asked the athletic trainer to go talk to my brass tech ... just let them know what's up ... the night before I got hit in the back of the head." Communication solidified a drum corps member's perception of an athletic trainer and gave peace of mind that her injury was being cared for in an appropriate manner. 
As mentioned with communication, the patient and clinician must have collaboration in order to be successful in their interactions. Charlie insisted, "it's believing that [the athletic trainer] will continue to help push me along especially in the team dynamic that we have." He continued on to say members have the power to help athletic trainers better understand what they are feeling:

It's kind of a partnership ... to tell them information to understand what's going on because a lot of stuff that they're dealing with is stuff that can't be seen. It's not like you have 'oh no, I'm bleeding!' It's not that. It's 'ow, my leg hurts.'

In some cases, working as a team created a quicker healing process or plan of action. Natalie described this idea further, "I guess knowing that I do my part and he'll do his part and you know if we work together then hopefully the situation might go away or at least get better." Overall, interaction whether in terms of communication or collaboration rendered best results when the participant and athletic trainer worked together as a unit.

\section{Drum Corps Members' Definition of Trust}

David's definition (2013) of trust encompassed aspects of having the patient's best interest in mind and assistance toward return to activity. Through the interviews, participants were asked what trust meant to them and to define it in their own words. Patrick, Luke, Natalie, Matthew, and Joe all discussed the perception of athletic trainers looking out for their well being and keeping the members' best interest in mind. Matthew elaborated on the concept as follows:

It means respecting somebody else's knowledge on the subject, if we're talking about medical expertise. Respecting their knowledge and their ability to provide accurate information to help you to the best of their ability and knowing that they want what's best for you. 
In reference to the idea of return to activity, Patrick, Charlie, and Matthew spoke about relying on another person to assist when unable to attain a goal by themselves. One participant described how he placed his goals for recovery in the hands of his athletic trainer with confidence hoping that person would not injure him or cause further impairment.

Similar to the results of David's study (2013), the participants struggled to define trust giving it much thought before answering with clarity. Charlie illustrated this point through a verbal self-debate, “Trust...that's a hard question. That's a hard question. (pause) Let's see. (sounds of tapping) (under his breath) What does trust mean to me?" The interviewer expected this response difficulty in which patience and adequate time was given in order to obtain thorough explanations. The idea of trust is inherently "wellknown" within our culture that it only appears abstract when deeply thinking about it.

Among the 12 participants, 10 stated that they personally trusted their athletic trainer. Caterinicchio (1979) noted the higher frequency of successful treatment outcomes increased positive health gains, therefore, establishing more trust in the physician-patient relationship. The trend proved to be true among the participants in this study as well. The success of an injury treatment directly correlated with a positive, trusting relationship between drum corps member and athletic trainer. Patrick explained, "the problem was handled very well and had such a huge impact on my ability to perform correctly." In a congruent manner, Luke replied, "my own personal issues were cared for right away and I thought that they were cared for as well as they could have been given the circumstances." 
For those who sustained fewer injuries and had less interaction with the athletic trainer, peer feedback became important. Maria justified her thought process while watching others receive care:

Mainly it was being able to trust them and seeing that they were able to help so many other people, I was like, 'Oh, okay well they know what they're doing,' because all these other people are having injuries fixed and being okay. It's like oh yeah I can totally go up to them and trust them.

With such a social activity, word of mouth travels fast and becomes the main source of credibility for new staff members among the corps. Luke stated, "[I] never heard of anybody having a bad experience with our athletic trainer or anyone who had an issue that needed to be dealt with." Through analysis, a few negative cases arose. Joe provided examples to explain distrust of his athletic trainer:

Um, the main reason [I did not trust them] was because they didn't do their job, um, as well as they should have... I feel that people had serious issues or they just brushed it off. 'Oh, you're just dehydrated,' 'oh, just drink a Gatorade,' 'oh, you'll be fine.'

Nathan further detailed his experiences at length in frustration: "I would say [as] my treatment went on, the less trustworthy I felt that they were, mostly because it was like, 'okay, you need to go to urgent care.' Are you kidding me? I could have told you this."

Though unlike the majority, these interpretations presented evidence to strengthen Caterinicchio's argument (1979) that treatment outcomes affect a patient's viewpoint of a clinician in addition to their willingness to return to that provider whether positive or negative in nature. In both cases, the participants' disdain toward trust was in relation to the same two athletic trainers. This exposes a direct reflection of those specific athletic trainers rather than the athletic training profession as a whole. Joe mentioned better 
experiences throughout his time in drum corps: "My first year I had a great experience with athletic trainers, but the past two years it has not been as great. So, I try and avoid [interaction] as much as possible throughout the summer." Trust held a tight grip on individuals as shown through the varied emotions displayed by participants. It was anticipated that gender would factor into trust within the patient-clinician relationship when handling sensitive injuries (Saemrow, 2016). Similar to the findings in Saemrow's study (2016), participants did not have a preference on gender of their athletic trainer and were more concerned with obtaining high-quality care. Emma joked about the matter:

It depends. If we're talking about caring for me then probably the same gender because I know that females have a more like motherly-like instinct, but if it's in terms like I'm falling off a building and I need someone to catch me I'm probably gonna choose like a big huge man, because he has more chances of catching me, you know?...(laughs) Nah, as long as they genuinely care, I'm open to either gender.

The impression of trust is simple, however, the components and attributes that comprise the value of trust is what creates complexity.

\section{Summary}

Through a qualitative investigation of drum corps members' perceptions of trust, two general categories and six higher order themes emerged. Each higher order theme corresponded with many raw data themes, which were found to facilitate or inhibit trust in varying capacities. The presentation of these categories further supported ties to previous research on the definition of trust, components of trust, and the patient-clinician relationship.

The participants discussed their experiences to give meaning toward their needs as performing artists, but also for understanding on how athletic trainers have shaped their 
ability to overcome injury and perform at a high level. The components of accessibility, clinical competence, dependability, comfort, and having a plan of action were deemed most important. In general, the participants felt trust to be an integral part in sustaining successful patient-clinician relationships. 


\section{Chapter 5: Conclusions and Recommendations}

The purpose of this study was to qualitatively examine the extent of trust held between drum corps members and athletic trainers. In addition, the research sought to determine factors that established or diminished trust in order to better understand how these factors facilitate a successful patient-clinician relationship. From the interviews, two general categories emerged: professional proficiency and interpersonal dynamics. Many of the participants discussed perceptions of trust and trust components closely aligned with past literature. Some of these included: the clinician caring for the patient's well being, the ability of a clinician to communicate with a patient on a personal level, consistency of medical staff, and a sense of benevolence.

It was reaffirmed that trust is a difficult concept to define. This study, however, brought attention to what trust means in the performing arts population. This perspective confirmed further how connotations and perceptions of trust can vary greatly depending on individual need. As seen consistently in prior literature and studies, it is imperative that a clinician practices within his or her medical scope while ensuring the patient's best interest is taken into account. Drum corps members approved of this trait in athletic trainers and stated its importance in reaching goals through recovery and injury progression.

In general, trust is present in the drum corps member-athletic trainer relationship and many factors were found to develop or hinder this interaction. An equal balance of professional and personal traits is ideal. As shown in other populations, success of injury treatment linked with a positive, trusting relationship in addition to retention of that 
patient. Participants wanted clear indication of clinical competence, but not at the sacrifice of an athletic trainer's ability to be friendly and approachable. Professionalism in the way the clinician handled him or herself through work and personal interaction influenced perception of trust (both positively and negatively). Having a plan of action during injury situations helped participants feel a sense of control over their treatment, but also progression toward a goal. It was noted many times that regardless of severity or mechanism of injury, individuals preferred their injury care to be personalized. This notion facilitated a higher level of trust with the athletic trainer.

Consistency of medical staff and accessibility to an athletic trainer was determined by participants to factor significantly into their opinions of performing arts health care. Due to inadequate staffing for the large-scale activity, timing and preparation were deemed crucial assets toward trust. Peer feedback and reputation were a means of evaluating an athletic trainer. Additionally, clinical credibility was gained through the athletic trainer being approachable and his or her willingness to care for participant ailments. It was an expectation that the athletic trainer served as an advocate for the drum corps member, communicating effectively through interpersonal connection and with staff members on behalf of the patient. Many personality traits were desired and attributed to being worthy of trust including comfort, altruism, empathy, and building personal connections.

Athletic trainers were seen as the appropriate health care provider for this activity in terms of educational background, experience, adaptability, clinical expertise, and interpersonal skills. Participants recognized the value of health care for musical 
performing artists with hopes of it continuing to expand and transform into a widely accepted necessity.

\section{Recommendations for Further Research}

With an established sense of trust and deeper understanding of factors that inhibit and facilitate trust in Drum Corps International, it would be wise to empirically measure these values across all of DCI through the Patient-AT Trust Instrument. This survey has been validated in other athletic training settings and would allow current DCI clinicians to determine if their actions promote or diminish trust and to alter current clinical practices if necessary. Having this type of knowledge could influence drum corps member adherence and intervention outcomes.

It is also important to note that these findings may not be directly transferable or generalizable to other performing arts organizations. Replicating this study or studying the aspect of trust in health care relationships across other performing arts circuits (such as dance or theatre) would decipher parallels and differences in other age brackets, levels of competition, and art forms. As Drum Corps International grows in number and continues to integrate medical programs as part of the organizational infrastructure, it may be useful to explore the perception of health care related needs in future research studies.

\section{Clinical Application}

It is worth noting that participants perceive trust as an important aspect of the patientclinician relationship. This study brings awareness to athletic trainers of the clinician traits holding significance to musical performing artists. Additionally, those working as 
athletic trainers with the drum corps population can use this analysis as a basis for their professional and personal interactions with members. This may give insight into a "needs analysis" for Drum Corps International in which their medical subcommittee, Marching Music Health and Wellness Program (MMHWP), can distribute to executive administrators, corps directors, and medical staff members. 


\section{References}

Anderson, L. \& Dedrick, R. (1990). Development of the trust in physician scale: A measure to assess interpersonal trust in patient-physician relationships. Psychological Reports, 67, 1091-1100.

Barefoot, J. C., Maynard, K.E., Beckham, J.C., Brummett, B.H., Hooker, K., \& Siegler, I.C. (1998). Trust, health, and longevity. Journal of Behavioral Medicine, 21, 517 526.

Bischof, R.O. (1994). Drum and bugle corps: medical problems and issues. Medical Problems of Performing Artists. 131-136.

Borum, R. (2010). The science of interpersonal trust. University of South Florida: Selected Works. 1-79.

Brown, J. (1997). What is theatre? Newton, MA: Focal Press.

Calnan, M. \& Rowe, R. (2008). Trust relations in a changing health service. Journal of Health Services Research and Policy, 13, 97-103.

Caterinicchio, R. P. (1979). Testing plausible path model of interpersonal trust in patient physician treatment relationships. Social Science and Medicine. 13A, 81-89.

Cengage. (n.d.). Professional theatre companies (year round). [Data file]. Retrieved from http://www.cengage.com/resource_uploads/static_resources/0495898074/24614/theat re_companies.html

Creswell, J., \& Miller, D. (2000). Determining Validity in Qualitative Inquiry. Theory Into Practice, 39(3), 124-130. Retrieved from http://www.jstor.org/stable/1477543

Dance USA. (2012). National company roster. [Data file]. Retrieved from http://www.danceusa.org/nationalcompanyroster

David, S. (2013). Development and validation of the patient-AT trust instrument. Published doctoral dissertation. Ohio University, Athens, Ohio.

Dick, R.W., Berning, J.R., Dawson, W., Ginsburg, R.D., Miller, C., \& Shybut, G.T. (2013). Athletes and the arts - the role of sports medicine in the performing arts. Current Sports Medicine Reports. 397-403. 
Dionisi, A. \& Brodt, S. (2008). Managing identities across the negotiation divide: the effect of intra-group trust development strategies in inter-group negotiations (November 9, 2008). IACM 21st Annual Conference Paper. Available at SSRN: http://ssrn.com/abstract $=1298515$

Day-by-day guide to the 2014 DCI World Championships. (2014, July 30). Retrieved January 12, 2015 from http://www.dci.org/news/view.cfm?news_id=1068a516-62804882-8679-b41feb1c58e2

Drum Corps International. (n.d.) Marching Music's Major League. Retrieved from http://www.dci.org

Dwyer, D., Liu, H., \& Rizzo, J. (2012). Does patient trust promote better care? Applied Economics. 44, 2283-2295.

Female Athlete Triad Coalition. (n.d.). The Female Athlete Triad. Retrieved from http://www.femaleathletetriad.org/for-professionals/what-is-the-triad/

Guest, G., Bunce, A., \& Johnson, L. (2006). How many interviews are enough? An experiment with data saturation and variability. Field Methods, 18, 59-82.

Hall, M. A., Dugan, E., Zheng, B., \& Mishra A. K. (2001). Trust in physicians and medical institutions: What is it, can it be measured, and does it matter? Milbank Quarterly, 79, 613-639.

Hall, M. A., Camacho, F., Dugan, E., \& Balkrishnan, R. (2002). Trust in the medical profession: Conceptual and measure issues. Health Services Research, 37, 14191439.

Homans, G. (1958). Social behavior as exchange. American Journal of Sociology, 63, 597-606.

Kramer, R. M. \& Tyler, T. R. (1996). Trust in organizations: Frontiers of theory and research. Sage Publications, Thousand Oaks, CA.

Magee, D.J., Manske, R.C., Zachazewski, J.E., Quillen, W.S. (2011). Musculoskeletal dance medicine and science. In J.A Russell (Ed.), Athletic and sport issues in musculoskeletal rehabilitation. (651-680). St. Louis, MO: Elsevier Saunders.

Manchester, R.A. (2009). Toward a performing arts medicine definition of performing arts. Medical Problems of Performing Artists. 101-102.

Marching band. (2014). In Dictionary.com online. Retrieved from http://dictionary.reference.com/browse/marching\%20band?s=t 
Mayer, R. C., Davis J. H., \& Schoorman F. D., (1995). An integrative model of organizational trust. Academy of Management Review, 20, 709-734.

McKnight, D.H., \& Chervany, N. (2001). What trust means in e-commerce customer relationships: an interdisciplinary conceptual typology. International Journal of Electronic Commerce, 6, 35-59.

Morgan, A. (2012). Call yourself a nurse! Defending the clinical credibility of educators and managers in intensive care. Nursing in Critical Care. 17, 271-274.

National Athletic Trainers' Association. (2007, June). Recommendations and Guidelines for Appropriate Medical Coverage of Intercollegiate Athletics. Retrieved from https://www.nata.org/sites/default/files/amciarecsandguides.pdf

National Athletic Trainers' Association. (n.d.) Performing Arts Setting. Retrieved from www.nata.org/athletic-training/job-settings/performing-arts-setting

National Band Association. (n.d.) NBA Fact Sheet. Retrieved from https://www.nationalbandassociation.org/

Ozawa, S. \& Sripad, P. (2013). How do you measure trust in the health system? A systematic review of the literature. Social Science \& Medicine. 91: 10-14.

Pape, D. (2014, October 7). More than just marching band: musical athletes redefine 'sport.' Austin Fit Magazine.

Patton, M. Q. (1999). Enhancing the quality and credibility of qualitative analysis. Health Services Research, 35, 1189-1208.

Performance art (n.d.). In Merriam-Webster Online. Retrieved from http://www.merriamwebster.com/dictionary/performance\%20art

Performing arts. (n.d.). In Oxford Dictionaries online. Retrieved from http://www.oxforddictionaries.com/us/definition/american_english/performingarts? $\mathrm{q}=$ performing + arts\&searchDictCode $=$ all

Peters, R., Covello, V., \& MacCallum, D. (1997). The determinants of trust and credibility in environmental risk communication: an empirical study. Risk Analysis, 17, 43-54.

Pitney, W. A., \& Parker, J. (2009). Qualitative research in physical activity and the health professions. Hampaign, IL: Human Kinetics. 
Radwin, L., Washko, M., Suchy, K., Tyman, K. (2005). Development and pilot testing of four desired health outcome scales. Oncology Nursing Forum. 32, 92-96.

Russell, J.A. \& Wang, T.J. (2012). Injury occurrence in university dancers and their access to healthcare. International Association for Dance Medicine and Science Annual Conference.

Russell, J.A. (2013). Preventing dance injuries: current perspectives. Open Access Journal of Sports Medicine. 199-210.

Saemrow, M. R. (2016). Does gender influence the patient-clinician relationship? (Order No. 10117038). Available from ProQuest Dissertations \& Theses Global. (1794655936). Retrieved from https://search.proquest.com/docview/1794655936?accountid=25318

Sankar, P., Mora, S., Merz, J., \& Jones, N. (2003). Patient perspectives of medical confidentiality. Journal of General Internal Medicine. 18, 663-665.

Siegle, J. (2015, January). Caring for the corps. National Athletic Trainers' Association News.

Schneider, I. K., Konijn, E. A., Righetti, F., \& Rusbult, C. E. (2011). A healthy dose of trust: The relationship between interpersonal trust and health. Personal Relationships, $18,668-676$.

Starnes, B.J., Truhon, S.A., \& McCarthy, V. (2010). Organizational trust: employeeemployer relationships. Human Development and Leadership. 1-15.

Steinberg, D. (2010). Altruism in medicine: Its definition, nature, and dilemmas. Cambridge Quarterly of Healthcare Ethics. 19, 249-250.

Tashakkori, T., \& Teddlie, C. (2010) Emergent Data Analysis Techniques in Mixed Method Research. In V. Knight (Ed.), SAGE Handbook of Mixed Methods in Social $\&$ Behavioral Research. (pp. 414-416). Thousand Oaks, CA: SAGE Publications, Inc.

Trust. (n.d). In Dictionary.com online. Retrieved from http://dictionary.reference.com/browse/trust?s=t

Trust. (n.d.). In Merriam-Webster online. Retrieved from http://www.merriamwebster.com/dictionary/trust

United Nations Educational, Scientific and Cultural Organization. (2012). Performing arts. Retrieved from http://www.unesco.org/culture/ich/?pg=54 
Weber, C. (2010). Cuts, callbacks \& contracts: an audition terminology primer. Retrieved from http://www.dci.org/news/view.cfm?news_id=d81403a6-b8c9-4b019dcb-17c7126c2f65

Weber, C. (2012). New judging system ready to debut June 16. Retrieved from http://www.dci.org/news/view.cfm?news_id=5bc74534-fd5c-43c6-a28d$78 \mathrm{c} 928 \mathrm{fdd} 00 \mathrm{a}$

Weber, J. M., Malhotra, D., \& Murnighan, J. K. (2005). Normal acts of irrational trust: Motivated attributions and the trust development process. Research in Organizational Behavior. 26(3): 75-101.

Willis, J. W., \& Jost, M. (2007). Frameworks for qualitative research. In L.C. Shaw (Ed.), Foundations of qualitative research: interpretive and critical approaches (pp. 162166). Thousand Oaks, CA: Sage Publications. 


\section{Appendix A: Oral/E-mail Script}

\section{Oral Script:}

Hi, my name is Jenna Chinburg. I am graduate student in the Kinesiology Department at San Jose State University and I am conducting a research study to evaluate the level of trust between drum corps members and athletic trainers. With this research, we hope to better understand the relationship between drum corps members and athletic trainers in addition to identifying factors that influence drum corps members' trust.

Would you like to hear more about my study?

[If yes, ]

You are invited to participate in this research study because you are a current Drum Corps International member between the ages of 16 and 22 years old. Additionally, you have had access and interaction with an athletic trainer through your drum corps. Your participation is entirely voluntary and you may change your mind or quit participating at any time, with no penalty; however, your assistance would be greatly appreciated in making this a meaningful study.

If you decide to participate, we will set up a time for an individual Skype interview. The interview should take one hour to complete and I will ask you questions about trust and your thoughts on past interactions with your athletic trainer. I also will ask for basic demographic information. With your permission, I will voice and video-record the interview to ensure accuracy. Once the interviews have been transcribed into a written document, I will erase the audio/video recordings.

When writing about the study, your information will be combined with information from other people taking part in the study. We will write about the combined information that was gathered. Your name and identifying demographics will not be used in the written materials. We may publish the results of the study; however, we will keep all identifying information private.

If you have any questions about the study later, you can contact me at (952)7381285 or jenna.chinburg@sjsu.edu. If you have questions about the rights of human participants in research, contact Pamela Stacks, Ph.D., Associate Vice President, the Office of Research, at 408-924-2479.

Thank you for agreeing to participate in this study. If you wish to receive a copy of this information in writing, please let me know and I will e-mail it to you. 


\section{E-mail Script}

Hello

My name is Jenna Chinburg. I am graduate student in the Kinesiology Department at San Jose State University and I am conducting a research study to evaluate the level of trust between drum corps members and athletic trainers. With this research, we hope to better understand the relationship between drum corps members and athletic trainers in addition to identifying factors that influence drum corps members' trust.

You are invited to participate in this research study because you are a current Drum Corps International member between the ages of 16 and 22 years old. Additionally, you have had access and interaction with an athletic trainer through your drum corps. Your participation is entirely voluntary and you may change your mind or quit participating at any time, with no penalty; however, your assistance would be greatly appreciated in making this a meaningful study.

If you decide to participate, we will set up a time for an individual Skype interview. The interview should take one hour to complete and I will ask you questions about trust and your thoughts on past interactions with your athletic trainer. I also will ask for basic demographic information. With your permission, I will audio/video record the interview to ensure accuracy. Once the interviews have been transcribed into a written document, I will erase the audio/video recordings.

When writing about the study, your information will be combined with information from other people taking part in the study. We will write about the combined information that was gathered. Your name and identifying demographics will not be used in the written materials. We may publish the results of the study; however, we will keep all identifying information private.

If you have any questions about the study or would like to agree to participate, please contact me at (952)738-1285 or jenna.chinburg@sjsu.edu. If you have questions about the rights of human participants in research, contact Pamela Stacks, Ph.D., Associate Vice President, the Office of Research, at 408-924-2479.

Thank you for your time,

Jenna Chinburg 


\section{Appendix B: IRB Approval Letter}
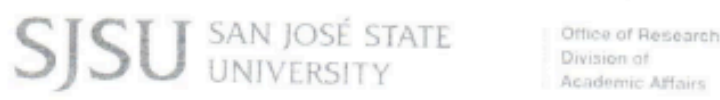

To: Jenna Chinburg

From: Pamela C. Stacks, Ph.D. Associate Vice President Office of Research

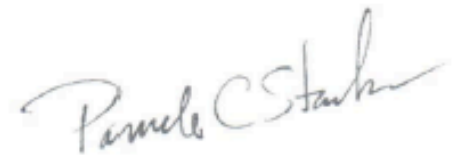

Date: December 9.2015

The Human Subjects-Institutional Review Board has approved your request to use human subjects in the study entitled: Artists"

"The Perception of Trust between Athletic Trainers and Musical Performing

This approval is contingent upon the subjects participating in your research project being appropriately protected from risk. This includes the protection of the confidentiality of the subjects' identity when they participate in your research project, and with regard to all data that may be collected from the subjects. The approval includes continued monitoring of your research by the Board to assure that the subjects are being adequately and properly protected from such risks. If at any time a subject becomes injured or complains of injury, you must notify Dr. Pamela Stacks immediately. Injury includes but is not limited to bodily harm, psychological trauma, and release of potentially damaging personal information. This approval for the human subject's portion of your project is in effect for one year, and data collection heyond December 9.2016 requires an extension request.

Please also be advised that all subjects need to be fully informed and aware that their participation in your research project is voluntary, and that he or she may withdraw from the project at any time. Further, a subject's participation, refusal to participate, or withdrawal will not affect any services that the subject is receiving or will receive at the institution in which the research is being conducted. If you have any questions, please contact me at (408) 924-2479.

Protocol \# S15215

ce. Masaaki Tsuruike 0054 


\section{Appendix C: Interview Protocol}

\section{Demographics}
a. Age?
b. Gender?
c. How many years have you participated in Drum Corps International?
d. How many years have you marched with your current drum corps?
e. Have you had consistent access to an athletic trainer for the duration of your drum corps experience?

If yes, how often was an athletic trainer available?

f. How often do you typically use an athletic trainer during the summer tour (May through August)? (daily, weekly etc.)

g. How many athletic trainers have you interacted with while participating in the marching arts?

h. How many injuries have you had since you started your career as a musical performing artist?

i. How would you rate the severity of your worst injury or illness on a scale from 0 to 10 ( 0 being no pain -10 being worst pain you've ever experienced) in your entire career of drum corps? What was your injury or illness?

$\mathrm{j}$. What is the longest time (number of visits, length of visits) in the course of one drum corps season you worked with an athletic trainer to address a marching related concern? (Clarify concern - injury, performance, etc.)

\section{Factors That Determine Whether to Seek Care or Not}

1. How do you think the injury rate of drum corps members compares to that of a traditional athlete? (such as a football player or soccer player)

a. With that said, do you believe musical performing artists require the same accessibility to medical personnel and resources as the traditional athlete?

2. What factors influence your decision to seek medical advice or care from your athletic trainer?

3. Is there anyone besides your athletic trainer you would rather seek medical care from?

If yes, who and why? 
4. What factors would make it less likely for you to approach your athletic trainer with an injury needing care?

5. What factors would make it more likely for you to approach your athletic trainer with an injury needing care?

6. Do you believe drum corps are equipped with the proper equipment, medical supplies, and staff to properly care for the injuries or illnesses acquired from the activity?

7. Do you believe athletic trainers have the proper skill set, knowledge, and experience to understand and care for the needs of drum corps members?

\section{How is trust defined?}

1. Is trust important to you?

2. Is trust in your athletic trainer and medical staff an important aspect to your general well-being and health while participating in drum corps?

3. What does trust mean to you?

a. Does trust mean something different when referring to your athletic trainer?

4. Do you trust your athletic trainer? Why or why not?

5. How did you come to the conclusion that your athletic trainer was trustworthy or not? Do you have a specific story to explain your response?

6. Who do you trust the most among your drum corps staff? Why?

7. Are you generally more willing to trust someone of the same gender or opposite gender? Why?

\section{What are the components of trust?}

1. What personality traits or characteristics does a trustworthy person possess?

a. Does your athletic trainer have any of these qualities?

2. Do you have a good relationship with your athletic trainer? What creates this $\operatorname{good} /$ poor relationship?

3. Do you feel like you can depend on your athletic trainer?

a. Why or why not? 
4. Do you prefer to have an explanation of what the athletic trainer's course of action is in regard to your injury or illness when being cared for?

5. Do you feel like you are working together as a team?

a. Does the athletic trainer take your input into consideration?

6. Do you think that you progressed appropriately with your injuries? Why or why not?

7. Does your athletic trainer seem to put your best interest in mind?

a. If yes, can you give me an example of this?

8. How does professionalism factor into your ability to trust medical personnel?

a. Does your athletic trainer exemplify appropriate professionalism for this activity?

9. How highly would another member's past experiences or recommendations of an athletic trainer influence your ability to trust them?

10. Do you believe your athletic trainer allots enough time with you individually to build a trusting relationship?

a. If yes, how much time does the athletic trainer typically spend with you?

11. Do you feel as though your athletic trainer personalizes your injury care specific to your needs?

Why or why not?

12. What else would you like to tell me that we have not discussed already? 


\section{Appendix D: Informed Consent Form}

\section{REQUEST FOR YOUR PARTICPATION IN RESEARCH}

\section{NAME OF THE RESEARCHER}

Jenna Chinburg, ATC; San Jose State graduate student

\section{PURPOSE}

The purpose of this study is to critically evaluate the amount of trust performing artists, specifically drum corps members, have in their athletic trainer. Researching this specific population will allow clinicians to better understand the needs of musical performing artists and more effectively facilitate the patient-clinician relationship.

\section{PROCEDURES}

Prior to research participation, you will complete the informed consent document and the researcher will answer any additional questions. For participants under the age of 18, a parent/legal guardian will be contacted via e-mail before the interview date in order to obtain consent for their child to participate in the study via parent/guardian permission form. If the parents consent, a participant youth assent form will also be completed by the participant prior to the start of the interview.

Once documentation is complete, you will be asked to complete one individual interview via Skype (or similar electronic method) with the primary researcher. The interview in total should last no longer than one hour. Demographic information will be collected in addition to responses to various questions about trust and your thoughts on past interactions with their athletic trainer. A digital voice recorder will be used to conduct and record the interview. All response will be kept confidential and demographic information will be coded so it cannot be traced back to a specific individual. All responses will be used solely for research purposes.

\section{POTENTIAL RISKS}

There are no known risks for participation in this study.

\section{POTENTIAL BENEFITS}

You are not expected to get any benefit from participating in the research study; however, benefits to others may include a better understanding of how athletic trainers fit into the realm of musical performing arts. 
The assessment of trust can determine how to improve the performer-athletic trainer relationship.

\section{COMPENSATION}

Participants will be compensated $\$ 25.00$ at the completion of their interview.

\section{CONFIDENTIALITY}

We will keep private all research records that identify participants. Participant information will be combined with information from other people taking part in the study. When writing about the study, we will write about the combined information that we have gathered. We may publish the results of the study; however, names and other identifying information will be kept private.

We will make every effort to prevent anyone who is not on the research team from knowing that you gave us information, or what that information is. For example, your name will be kept separate from your research records and these two things will be stored in different places under lock and key.

If you withdraw before the research is over, your information will be removed at your request, and we will not collect additional information about you.

\section{TITLE OF THE STUDY}

The Perception of Trust Between Athletic Trainers and Musical Performing Artists

\section{PARTICIPANT RIGHTS}

Your participation in this study is completely voluntary. You can refuse to participate in the entire study or any part of the study without any negative effect on your relations with San Jose State University. You also have the right to skip any question you do not wish to answer. This consent form is not a contract. It is a written explanation of what will happen during the study if you decide to participate. You will not waive any rights if you choose not to participate, and there is no penalty for stopping your participation in the study.

\section{QUESTIONS OR PROBLEMS}

You are encouraged to ask questions at any time during this study.

- For further information about the study, please contact Jenna Chinburg, 952-738-1285 or jenna.chinburg@sjsu.edu

- Complaints about the research may be presented to Dr. Matt Masucci, 408-924-3010. 
- For questions about participants' rights or if you feel you have been harmed in any way by your participation in this study, please contact Dr. Pamela Stacks, Associate Vice

President of the Office of Research, San Jose State University, at 408-924-2479.

\section{SIGNATURES}

Your signature indicates that you voluntarily agree to be a part of the study, that the details of the study have been explained to you, that you have been given time to read this document, and that your questions have been answered. You will receive a copy of this consent form for your records.

\section{Participant Signature}

Participant's Name (printed)

Participant's Signature

Date

\section{Researcher Statement}

I certify that the participant has been given adequate time to learn about the study and ask questions. It is my opinion that the participant understands his/her rights and the purpose, risks, benefits, and procedures of the research and has voluntarily agreed to participate.

Signature of Person Obtaining Informed Consent

Date 
Appendix E: Parent/Guardian Consent Form

\section{REQUEST FOR YOUR CHILD'S OR WARD'S PARTICIPATION IN RESEARCH}

\section{TITLE OF THE STUDY}

The Perception of Trust Between Athletic Trainers and Musical Performing Artists

\section{NAME OF THE RESEARCHER}

Jenna Chinburg, ATC; San Jose State University graduate student

\section{PURPOSE}

The purpose of this study is to critically evaluate the amount of trust performing artists, specifically drum corps members, have in their athletic trainer. Researching this specific population will allow clinicians to better understand the needs of musical performing artists and more effectively facilitate the patient-clinician relationship.

\section{PROCEDURES}

Prior to research participation, a parent/legal guardian will be contacted via e-mail for those under the age of 18 in order to obtain consent for their child to participate in the study via parent/guardian permission form. If the parents consent, a participant youth assent form will also be completed by the participant prior to the start of the interview.

Once documentation is complete, your child will be asked to complete one individual interview via Skype (or similar electronic method) with the primary researcher. The interview in total should last no longer than one hour. Demographic information will be collected in addition to responses to various questions about trust and your child's thoughts on past interactions with their athletic trainer. A digital voice recorder will be used to conduct and record the interview. All response will be kept confidential and demographic information will be coded so it cannot be traced back to a specific individual. All responses will be used solely for research purposes.

\section{POTENTIAL RISKS}

There are no known risks for participating in this study. 


\section{POTENTIAL BENEFITS}

Your child is not expected to get any benefit from participating in the research study; however, benefits to others may include a better understanding of how athletic trainers fit into the realm of musical performing arts. The assessment of trust can determine how to improve the performer-athletic trainer relationship.

\section{COMPENSATION}

Participants will be compensated $\$ 25.00$ at the completion of their interview.

\section{CONFIDENTIALITY}

We will keep private all research records that identify participants. Participant information will be combined with information from other people taking part in the study. When writing about the study, we will write about the combined information that we have gathered. We may publish the results of the study; however, names and other identifying information will be kept private.

We will make every effort to prevent anyone who is not on the research team from knowing that your child gave us information, or what that information is. For example, your child's name will be kept separate from your research records and these two things will be stored in different places under lock and key.

If your child withdraws before the research is over, his/her information will be removed at your request, and we will not collect additional information about him/her.

\section{PARTICIPANT RIGHTS}

Your child's participation in this study is completely voluntary. You may refuse to allow his or her participation in the entire study or any part of the study without any negative effect on your relations with San Jose State University or [name any other participating institutions]. Your child also has the right to skip any question that he or she does not wish to answer. This consent form is not a contract. It is a written explanation of what will happen during the study if you decide to allow your child to participate. You will not waive any rights if you choose not to allow your child to participate and there is no penalty for stopping your child's participation in the study. Your child may also decide to stop at any time.

\section{QUESTIONS OR PROBLEMS}

You are encouraged to ask questions at any time during this study. 
- For further information about the study, please contact Jenna Chinburg, 952-7381285 or jenna.chinburg@sjsu.edu

- Complaints about the research may be presented to Dr. Matt Masucci, 408-9243010.

- For questions about participants' rights or if you feel you have been harmed in any way by your participation in this study, please contact Dr. Pamela Stacks, Associate Vice President of the Office of Research, San Jose State University, at 408-924-2479.

\section{SIGNATURES}

\section{Parent/Guardian Signature}

Your signature indicates that you voluntarily agree to allow your child to be part of the study, that the details of the study have been explained to you and your child, that you have been given time to read this document, and that your questions have been answered. You will be given a copy of this consent form, signed and dated by the researcher, to keep for your records.

Name of Child or Minor Parent or Guardian Name (Printed)

Relationship to Child or Minor Parent or Guardian Signature Date

\section{Researcher Statement}

I certify that the minor's parent/guardian has been given adequate time to learn about the study and ask questions. It is my opinion that the parent/guardian understands his/her child's rights and the purpose, risks, benefits, and procedures of the research and has voluntarily agreed to allow his/her child to participate. I have also explained the study to the minor in language appropriate to his/her age and have received assent from the minor. 
Appendix F: Child Assent Form

Child Assent Form

\section{REQUEST FOR YOUR PARTICIPATION IN A RESEARCH STUDY}

\section{TITLE OF THE STUDY}

The Perception of Trust Between Athletic Trainers and Musical Performing Artists

\section{NAME OF THE RESEARCHERS}

Jenna Chinburg, ATC; San Jose State University graduate student

\section{WHAT THE RESEARCH IS ABOUT}

You are invited to participate in a research study evaluating the amount of trust musical performing artists have in their athletic trainer.

\section{WHAT YOU WILL BE ASKED TO DO}

You will be asked to complete a one (1) hour interview via Skype with the researcher. Questions will include demographics, your general perception of trust, and how trust has affected your past interactions with athletic trainers. You do not need to answer questions that you do not know the answer to or that make you uncomfortable. Each interview will be audio/video recorded to assist with transcription.

\section{RISKS AND BENEFITS OF PARTICPATION}

We do not anticipate that there are any risks associated with participating in this study. You will not directly benefit from participation in the study, however, benefits to others may include a better understanding of how athletic trainers fit into the realm of musical performing arts. The assessment of trust can determine how to improve the performerathletic trainer relationship.

\section{INCENTIVES FOR PARTICIPATION}

Participants will receive $\$ 25.00$ at the completion of their interview.

\section{CONFIDENTIALITY}

Although the results of this study may be published, no information that could identify you or your parents will be included. We will only report information in a way that could not be traced back to a specific individual. To ensure the privacy of the information you 
provide, we will store all research materials in a password protected and encrypted file on a password protected computer that only the research team has access to.

\section{WHO TO CONTACT IF YOU HAVE QUESTIONS}

If you have questions at any time during the study, the people listed below can be contacted.

Questions about this research may be addressed to Jenna Chinburg, ATC, at 952-7381285. Complaints about the research may be presented to Dr. Matt Masucci, Department Chair of Kinesiology, at 408-924-3010. For questions about your rights or to report a research- related injury, contact Pamela Stacks, Ph.D., Associate Vice President, the Office of Research, at 408-924-2479.

\section{WHAT YOUR RIGHTS ARE}

No service of any kind to which you are otherwise entitled will be lost or at risk if you decide not to participate in this study. Your assent (agreement) is voluntary. You may refuse to participate in the entire study or in any part of the study. You have the right to not answer any questions you do not wish to answer. If you decide to participate in the study, you are free to quit at any time without any negative effect on your relations with Drum Corps International and/or your respective drum and bugle corps.

\section{SIGNATURES}

Your signature indicates that you voluntarily agree to participate in the study, that the details of the study have been explained to you, that you have been given time to read this document, and that your questions have been satisfactorily answered. You will receive a copy of this consent form for your records.

Participant's Name (printed) 


\section{RESEACHER STATEMENT}

In my judgment the minor/youth is voluntarily and knowingly giving assent to participate in this research study. Consent from the parent or guardian has also already been sought and obtained.

Jenna Chinburg, ATC

Date 